\title{
Rich nations, poor nations: how much can multiple equilibria explain?
}

\author{
Bryan S. Graham and Jonathan Temple \\ CID Working Paper No. 76 \\ September 2001
}

Copyright 2001 Bryan S. Graham, Jonathan Temple and the President and Fellows of Harvard College

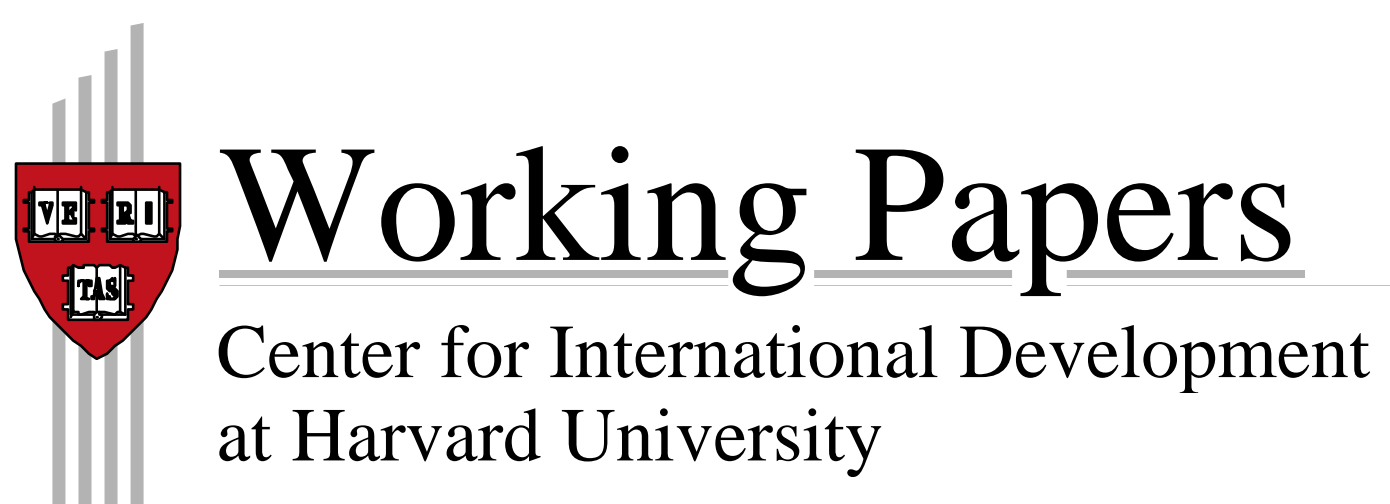




\title{
Rich nations, poor nations:
}

\section{how much can multiple equilibria explain? ${ }^{1}$}

\author{
Bryan S. Graham and Jonathan Temple
}

\begin{abstract}
The idea that income differences between rich and poor nations arise through multiple equilibria or 'poverty traps' is as intuitive as it is difficult to verify. In this paper, we explore the empirical relevance of such models. We calibrate a simple two sector model for 127 countries, and use the results to analyze the international prevalence of poverty traps and their consequences for productivity. We also examine the possible effects of multiplicity on the world distribution of income, and identify events in the data that may correspond to equilibrium switching.
\end{abstract}

Keywords: poverty traps, multiple equilibria, 'Big Push', TFP differences, calibration methods.

JEL Codes: C00, O14, O41, O47

Bryan S. Graham is a doctoral student in the Economics Department at Harvard University and a Graduate Student Fellow at the Center for International Development (bgraham@fas.harvard.edu)

Jonathan Temple is a Professor of Economics at Bristol University in the United Kingdom. (jon.temple@bristol.ac.uk)

1 We would like to thank Gavin Cameron, Francesco Caselli, Michael Kremer, Andrew Mountford, Stephen Redding, Dani Rodrik and Mathan Satchi for helpful comments and discussion. We are also grateful to seminar participants at Harvard, Oxford, and the 2001 European Winter Meeting of the Econometric Society. Graham would like to thank the Rhodes Trust, the George Webb Medley Endowment Fund, the National Science Foundation, and the Ford Foundation for financial support during various phases of the research leading to this paper. Temple would like to thank the University of Oxford to which he was affiliated between 1996 and 2000. 


\section{Introduction}

This paper attempts to offer a fresh perspective on one of the oldest and most important questions in economics: why are some nations rich and others poor? We will draw on a familiar answer, namely the potential role of multiple equilibria or 'poverty traps', but our main contribution is not a theoretical one, nor a simple extension of previous work. Instead, we address what is probably the central weakness of this literature, namely its failure to explore the practical relevance of the poverty trap idea.

Our proposed solution involves several innovations. We develop a method for calibrating models with multiple equilibria. We apply this technique to a simple two sector model, and calibrate the model for 127 countries. The calibration exercise allows us to infer, under the maintained assumptions of our model, whether each country is in a low output or high output equilibrium. We can then examine the international prevalence of poverty traps, quantify their consequences for productivity, and even identify events in the data that may correspond to equilibrium switching. We can also shed new light on several unresolved debates in the growth literature, including the role of total factor productivity in explaining international differences in living standards. Overall, the implications are sufficiently rich that our approach may be a useful way forward for research on aggregate development.

Although calibration is an established technique in other areas of macroeconomics, we believe that its application to poverty traps is new to this paper. In pursuing this application, we also develop a method for calibrating models of multiple equilibria that may have wider application. The paper demonstrates how to exploit the multiplicity property in a way that greatly simplifies the calibration exercise. Given also the relatively simple form of our two sector model, our approach 
requires only a minimal set of parameter assumptions and remarkably little data. This is a considerable strength in any exercise that brings a specific model of aggregate development to the cross-country data.

Before we describe the approach in more detail, it is worth setting out the reasons that models of multiple equilibria continue to be of interest. The central argument is that the gulf between rich and poor countries does not originate simply in differences in characteristics like those of geography or institutions. Instead, there is a multiplicity in possible outcomes for any given set of characteristics. A country may be trapped in an equilibrium with low living standards when, in principle at least, an alternative and superior equilibrium is also feasible.

The concept of a poverty trap is among the oldest, most influential, and most controversial ideas in development economics. It has been discussed by a long list of distinguished economists, including Rosenstein-Rodan (1943), Nurkse (1953), Myrdal (1957), Murphy, Shleifer and Vishny (1989), Matsuyama (1991) and Krugman (1995) among many others. ${ }^{1}$ Recent formal modelling has helped to capture some of the central ideas using coherent theoretical frameworks. This seems worthwhile because the underlying ideas retain a powerful hold on our intuitions about development, and appear in many informal accounts of the growth process. For example, a common implication of models with multiplicity is the need for a critical minimum effort or 'Big Push' to bring about industrialization and development. These models can also yield transitions of unusually rapid growth driven by 'cumulative causation' (or a virtuous circle) as the economy moves from one equilibrium to another. In this sense, the models can capture the popular idea of take-off into sustained growth.

Despite the intuitive appeal of these ideas and their continuing prominence within the literature, it would perhaps be fair to say that formal models have not fulfilled their early promise. The reason is not hard to find: theoretical work has rarely generated distinctive implications that can be tested against the available data. $^{2}$ Despite the surge of interest in empirical growth research since the late 1980s, only a few papers have acknowledged the possibility of non-uniqueness. Conventional regression methods are not well suited to the analysis of multiple equilibria, and are likely to yield misleading results in this context (Durlauf and

\footnotetext{
${ }^{1}$ Our list emphasizes models in the "Big Push" tradition, often based on two sectors. For more general analysis of poverty traps, see Azariadis (1996, 2001). It is also worth noting that the possibility of multiple equilibria is discussed informally even in Solow's (1956) original exposition of the neoclassical growth model.

${ }^{2}$ Theoretical emphasis on multiple equilibria is sometimes justified with brief allusions to countries which display very different living standards, even when apparently similar in most other respects. Unfortunately, testing this claim in more rigorous terms is not straightforward, and has rarely been attempted.
} 
Johnson 1995, Durlauf and Quah 1999).

It will clearly be difficult to test models of multiple equilibria, and the aim of this paper is less ambitious. ${ }^{3}$ Our main contribution is to use calibration to address questions that are typically unanswered by purely theoretical work. For example, by calibrating a specific model, we can quantify the output effect of moving from one equilibrium to another. That allows some insight into the potential explanatory power of the model, and we can start to assess whether the disparity between low income and high income outcomes is large enough to help in understanding the vast international differences in living standards.

The paper will show that even a relatively simple model of multiplicity has rich empirical implications. As noted earlier, under the maintained assumptions of our model, we can use the available data to infer whether a given country is in a low output or high output equilibrium. These equilibrium assignments will be sensitive to parameter choices, and we explore the conditions on parameters under which a large or small number of the world's countries might be regarded as in a 'poverty trap' at a specific point in time. We can also compare the current distribution with a counterfactual one, generated by assuming that each country is in its high output equilibrium. Hence we can start to quantify the potential contribution of multiplicity to the observed cross-country variation in levels of income.

The exercise sheds light on other questions as well. Much recent work has investigated the extent and nature of international differences in total factor productivity (TFP). One motivation for this work is the argument that the costless transfer of technology across national borders should largely eliminate such differences. Yet aggregate 'levels accounting' exercises indicate that TFP differences across countries are large, and account for a substantial fraction of the variation in the output data. An approach based on multiplicity can potentially reconcile these two apparently conflicting positions. The reason is that, since models of multiple equilibria imply several possible output levels for fixed stocks of labor and capital, they can provide an explanation for international differences in aggregate TFP even when countries use the same technology.

The paper also examines the likelihood of switching between equilibria. We calibrate the model for two points in time, 1965 and 1988. Taken at face value, our calibration results indicate that some countries switched from a low output to a high output equilibrium over this period. By trying to isolate patterns in the cross-country data that could reflect transitions between equilibria, we can suggest which countries might repay detailed study when analyzing multiplicity in more

\footnotetext{
${ }^{3}$ We do not wish to imply that such models could never be tested. In the long term, it is possible that formal tests could be developed based on, for example, regime-switching models. As we emphasize later in the paper, our version of calibration should be seen as a complementary approach, and is not a substitute for formal testing.
} 
depth. ${ }^{4}$ This also means that we can relate our calibration results to nonparametric studies of the world income distribution, including the transition matrix approach associated with the work of Quah (1993).

These are ambitious goals, and some qualification is required. We do not use calibration to attempt to predict or match the patterns observed in the cross-country data. Instead, our aim is to learn more about the properties of a specific model, and its potential for explaining certain features of the data under plausible parameter assumptions. We hope to show that the insights gained from calibration are sufficiently rich to indicate that it provides a useful complement to theory. Nevertheless, one must be careful to remain agnostic on the validity of any particular model, and we acknowledge that some of our findings are inevitably speculative.

The paper is structured as follows. Section 2 sets out the model and provides some intuition for the presence of multiple equilibria. Section 3 introduces our calibration strategy. Section 4 provides a brief description of the data we use and discusses the main parameter assumptions. Sections 5 through 7 present our main results. Section 5 focuses on our main research question - posed in the title of the paper - namely, how much of the worldwide dispersion in income levels can multiple equilibria explain? Section 6 looks at the implications of the model for understanding aggregate TFP differences across countries. Section 7 relates our results to the nonparametric studies of the world distribution of income associated with Quah (1993) and others. Section 8 examines the possible sensitivity of the results to alternative parameter assumptions. Finally, section 9 provides a summary and conclusions.

One further note is in order. Since the approach is a new one, we lay out our ideas and methods in some detail, in the interests of clarity. This, combined with the richness of the model's implications, means that the paper is necessarily long. The more technical aspects of the model and the calibration exercise are described in the appendices.

\section{The model}

The model that we calibrate is probably the simplest that generates multiplicity in an interesting way, while remaining rich enough to take to the data. There are two sectors, agriculture and non-agriculture, and our key assumption is to posit externalities in the non-agricultural sector. The external effect means that we can

\footnotetext{
${ }^{4}$ For example, Rodrik $(1995,1996)$ has argued that the East Asian miracle may have depended on a state-assisted process of overcoming coordination failure, and a consequent shift between two different equilibrium output levels. A calibrated model could offer additional insight into the validity of this argument.
} 
assume constant returns to scale for individual firms, but allow increasing returns to scale at the level of the sector as a whole. As Romer (1986) showed in the context of aggregate growth models, the externality assumption can be a useful way to incorporate increasing returns in a general equilibrium context. For precisely this reason, two sector models with a sector-specific externality have a long history in trade theory, and form one of the canonical approaches to the analysis of multiple equilibria. $^{5}$

We start by sketching a very basic model, simpler than the one we calibrate. This simple model helps to convey the underlying ideas behind the multiplicity result, and we will return to it later, in explaining our calibration strategy. In the simple model, there is just one factor of production, labor. There are diminishing returns to labor in agriculture and, due to an externality, increasing returns to labor in non-agriculture. We assume that the relative price of the agricultural good is fixed. We also assume that labor is paid its private marginal product in both sectors.

The agricultural production function is:

$$
Y_{a}=A_{a} L_{a}^{\phi}
$$

where $0<\phi<1$. For non-agriculture, we introduce a simple form of externality, namely that the output of each individual firm is an increasing function of total non-agricultural employment. Using $j$ to index the firms, we have:

$$
Y_{n j}=A_{n} L_{n j} L_{n}^{\lambda}
$$

where $Y_{n j}$ and $L_{n j}$ are the output and employment of firm $i$ and $L_{n}$ is total employment in this sector. The externality parameter is greater than zero $(\lambda>0)$. Aggregating over firms we then have:

$$
Y_{n}=A_{n} L_{n}^{1+\lambda}
$$

The firms set employment levels $L_{n j}$ without taking into account their effect on total employment $L_{n}$. Hence, the private marginal product and wage in the non-agricultural sector is given by $w_{n}=A_{n} L_{n}^{\lambda}$.

We focus on equilibria with incomplete specialization, for which the wage is the same in both sectors. Defining $a=L_{a} / L$ where $L=L_{a}+L_{n}$ is total employment, the equality of wages implies:

$$
a^{1-\phi}(1-a)^{\lambda}=\phi\left(\frac{A_{a}}{A_{n}}\right) L^{\phi-1-\lambda}
$$

\footnotetext{
${ }^{5}$ In the theoretical literature on poverty traps, the presence of agglomeration economies arises from explicitly modelled microfoundations, such as a division of labor process (see for example Rodriguez-Clare 1996 or Rodrik 1996). Here we concentrate on a simpler model which captures the same basic ideas.
} 
This equation will usually yield two solutions for the agricultural employment share, $a$, where $0<a<1$. This is the multiplicity result. The underlying intuition is that, due to the externality, the labor demand curve in non-agriculture is upward sloping. ${ }^{6}$ Hence it may intersect more than once with the downward sloping labor demand curve in agriculture. When we turn to the more complex model that is the basis for our empirical work, we provide a more formal treatment of non-uniqueness.

The more complex model we calibrate retains the same basic structure, but introduces two additional factors, land and physical capital. Land is used only in agriculture, capital in both sectors. One advantage of introducing capital is that we can now make the more plausible assumption that returns to labor are diminishing, while retaining the implication of multiple equilibria, under the assumption that capital is perfectly mobile between sectors.

We now describe the full model in more detail. Essentially it is a general equilibrium model of production, as commonly used in trade theory. We consider a small open economy in which all goods are traded, but which is closed to international flows of capital and labor. Aggregate output is the sum of agricultural output, $Y_{a}$, and non-agricultural output, $Y_{n}$ :

$$
Y=Y_{a}+p Y_{n}
$$

where $p$ is the relative price of the non-agricultural good. Our assumptions about trade ensure that $p$ is fixed by world prices; appropriate choice of units for output allows the price to be eliminated from the equations that follow.

The model assumes that all factors of production are fully employed and that factors receive their private marginal products. We treat the agricultural sector as made up of a large number of landowners and perfectly competitive, profitmaximizing firms. ${ }^{7}$ These firms produce using a Cobb-Douglas technology that has constant returns to physical capital, land and labor, where land is rented from the landowners, and all firms pay the same factor costs. Under these assumptions we can restrict attention to a representative firm, and write total agricultural output as:

$$
Y_{a}=\left[\bar{K}-K_{n}\right]^{\alpha}[\bar{R}]^{\beta}\left[A_{a} h\left(\bar{L}-L_{n}\right)\right]^{1-\alpha-\beta}
$$

Where $\bar{K}, \bar{L}$, and $\bar{R}$ refer respectively to the aggregate (economy-wide) stock of capital, the total labor force, and a fixed quantity of land. For the sake of our later

\footnotetext{
${ }^{6}$ Note that the simple one-factor model is essentially similar to models analyzed by Panagariya (1981) and Ethier (1982b), both of whom provide richer intuition for the presence of multiple equilibria.

${ }^{7}$ A natural extension would be to model the decisions of rural households rather than firms.
} 
empirical work on productivity differences, we are also allowing the effectiveness of labor to be augmented by an index of human capital, $h$. Labor-augmenting technology is indexed by $A_{a}$.

In the non-agricultural sector, output for firm $j=1 . . J$ in non-agriculture is given by:

$$
\begin{aligned}
Y_{n j} & =f\left(K_{n j}, A_{n} h L_{n j}\right) v\left(Y_{n}\right) \\
& =f\left(k, A_{n} h\right) v\left(Y_{n}\right) L_{n j}
\end{aligned}
$$

where $f($.$) exhibits constant returns to scale, k$ is the capital-labor ratio, and $h$ is an index of average human capital. The second line follows from the use of constant returns technology by profit-maximizing firms. As is standard, the assumption that all firms within this sector pay the same factor costs, and use the same technology, ensures that all firms choose the same capital-labor ratio.

Note that each firm's output is also a function of total non-agricultural output, $Y_{n}$, which could reflect the presence of agglomeration economies or other external effects. In order to retain a standard treatment of competitive equilibrium, we assume that each firm is small enough to disregard its effect on total output. We write total non-agricultural output as:

$$
\begin{aligned}
Y_{n} & =\sum Y_{n j}=f\left(k, A_{n} h\right) v\left(Y_{n}\right)\left(\sum L_{n j}\right) \\
& =f\left(\sum K_{n j}, A_{n} h \sum L_{n j}\right) v\left(Y_{n}\right) \\
& =f\left(K_{n}, A_{n} h L_{n}\right) v\left(Y_{n}\right)
\end{aligned}
$$

For simplicity, we will take $f($.$) to be Cobb-Douglas, given by f()=.K_{n}^{\gamma}\left(A_{n} h L_{n}\right)^{1-\gamma}$. We also assume that $v\left(Y_{n}\right)=Y_{n}^{\frac{\lambda}{1+\lambda}}$. Then output in non-agriculture is

$$
Y_{n}=\left[K_{n}\right]^{\gamma(1+\lambda)}\left[A_{n} h L_{n}\right]^{(1-\gamma)(1+\lambda)}
$$

where the key parameter $\lambda$ captures the magnitude of agglomeration effects. For example $\lambda=0.3$ implies that if all non-agricultural firms simultaneously increase their use of capital and labor by 10 percent, total non-agricultural output would rise by 13 percent (from $1.1^{1.3} \approx 1.13$ ). The presence of increasing returns means that labor productivity depends on the scale of the sector.

Another way to judge assumptions about $\lambda$ is to observe that we can use equation (5) to derive an expression for labor productivity in non-agriculture:

$$
\frac{Y_{n}}{L_{n}}=\left[\frac{K_{n}}{L_{n}}\right]^{\gamma(1+\lambda)}\left[A_{n} h\right]^{(1-\gamma)(1+\lambda)} L_{n}^{\lambda}
$$

This means that $\lambda$ can be interpreted as the elasticity of labor productivity in nonagriculture with respect to non-agricultural employment, holding the capital-labor 
ratio constant. For example, if $\lambda=0.3$, then for two countries with the same capital-labor ratio in non-agriculture (and the same technology and human capital) a country that has $10 \%$ more non-agricultural employment than the other will have $3 \%$ higher labor productivity in non-agriculture.

We now discuss our treatment of human capital. From the perspective of calibrating the model for individual countries, our decision to augment labor in both sectors by the same skills factor, $h$, is equivalent to merely changing the scale of the productivity terms $A_{a}$ and $A_{n}$. Nevertheless, we choose to include an explicit role for human capital at this stage, because cross-country variation in skills will influence our later calculations of international variation in measures of productivity.

The model is completed by specifying equilibrium conditions. We assume that capital is perfectly mobile between sectors, so that rental rates are equalized. ${ }^{8}$

$$
r_{n}=r_{a}
$$

The second equilibrium condition applies to the labor market. Here we leave open the possibility of a sustained wage differential:

$$
w_{n}=w_{a}(1+\delta)
$$

This differential could reflect costs of migration or disutility from urban life, or perhaps some degree of risk aversion together with a lack of informal insurance mechanisms in urban areas. ${ }^{9}$ As we will see in calibrating the model, the data appear to imply significant intersectoral differentials under plausible parameter assumptions. Therefore we allow such differentials to be a potential feature of the equilibrium solution of the model. The extent of the differential will have implications for the output gain associated with an equilibrium switch, and we explore this issue later in the paper.

An equilibrium for our model is defined by an intersectoral allocation of capital and labor such that equations (6) and (7) hold simultaneously. ${ }^{10}$ These equilibrium conditions will typically be satisfied by more than one allocation of labor, and in the next section we will present conditions which indeed ensure two interior equilibria. These different allocations will be associated with different levels of

\footnotetext{
${ }^{8}$ The results are easily generalized to allow for a permanent differential in rental rates across sectors.

${ }^{9}$ Banerjee and Newman (1998) discuss insurance mechanisms in the context of a dual economy. Also, note that our assumption of a fixed wage differential could be justified by efficiency wage considerations, as in Landon-Lane and Robertson (2000).

${ }^{10}$ There is another equilibrium where all the labor force will be engaged in agricultural production. Since this is never observed in the data, the paper considers only interior equilibria, corresponding to incomplete specialization.
} 
aggregate output per worker and total factor productivity, and also with different factor shares and returns to capital and labor.

The multiplicity property is driven by the externality in the non-agricultural sector, which yields returns to scale that are increasing for the non-agriculture sector as a whole. Given that capital is mobile, this externality offsets diminishing returns to labor, and there will be a range of intersectoral labor allocations for which the returns to labor in non-agriculture are increasing in the number of people employed in the sector.

To see this more formally, note that if capital mobility ensures that rental rates are equalized, the capital stock employed in the non-agricultural sector, $K_{n}$, will be a function of non-agricultural employment $L_{n}$ and the fixed constants $\theta=\left(\lambda, \gamma, \alpha, \beta, \bar{K}, \bar{D}, \bar{L}, h, A_{a}, A_{n}\right)$. Hence we can write $K_{n}=\varphi\left(L_{n}, \theta\right)$ and this implies that the wage in each sector can be written as a function of $L_{n}$ and $\theta$ alone. In terms of an equilibrium condition,

$$
w_{n}\left(L_{n} ; \theta\right)=(1+\delta) w_{a}\left(L_{n} ; \theta\right)
$$

Hence we have reduced our two equilibrium conditions to a single equation in one unknown, namely non-agricultural employment $L_{n}$. This is one element of the strategy we will use to calibrate the model.

Figure 1 graphs the right and left-hand-sides of (8) for the case with no equilibrium wage differential $(\delta=0)$. These lines show agricultural and non-agricultural wages as a function of non-agricultural employment, so an equilibrium is defined by the intersection of these two curves. The figure illustrates the case where the curves intersect twice, corresponding to the presence of two interior equilibria. This is the usual case in our model, as we will discuss later in the paper.

We end our description of the model with an important digression, on the relevance of dynamics to our empirical analysis. In calibrating the model, we will not specify a mechanism for capital and labor movements away from equilibrium. Essentially we will be comparing outcomes under alternative, static equilibria. Consideration of the dynamics remains relevant, however. Depending on the form of the adjustment mechanisms for capital and labor, one of the equilibria may be locally unstable, and thus unlikely to be observed in practice.

We have established that local stability for both the interior equilibria is a possible outcome, given a suitably specified intersectoral labor migration process. This is a surprising result since standard approaches to stability analysis - for example positing a Marshallian adjustment process with $\delta=0$ as depicted in Figure 1 - would imply that the first interior equilibrium is unstable. ${ }^{11}$ This is not true,

\footnotetext{
${ }^{11}$ This feature is familiar from related models in the literature, including Panagariya (1981), Diamond (1982), Ethier (1982a, 1982b), Krugman (1991), and Matsuyama (1991).
} 


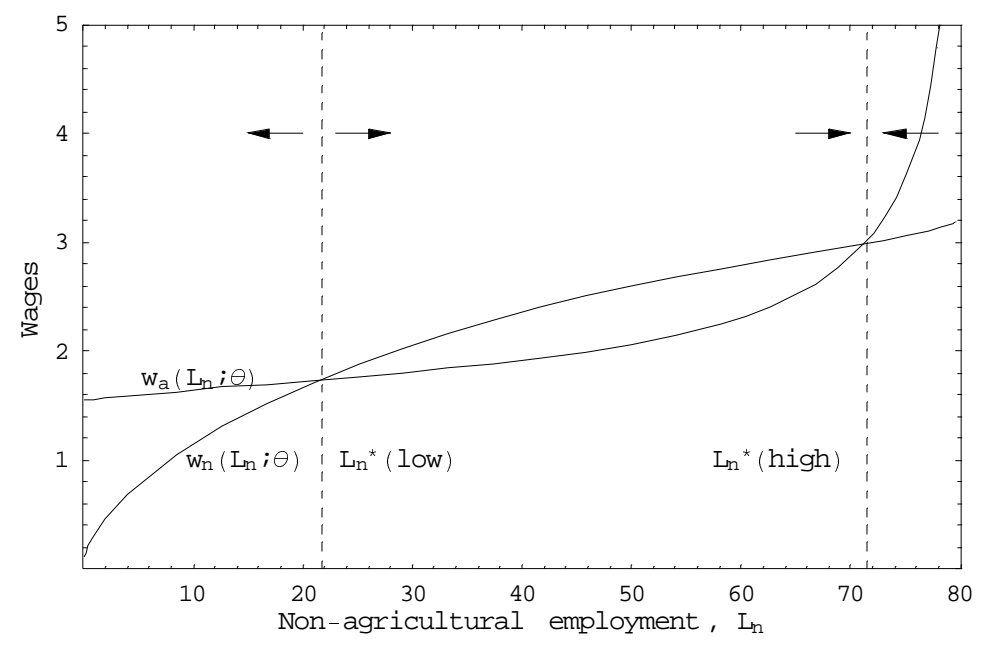

Figure 1: InCREASING RETURNS AND MULTIPLE EQUILIBRIA

NOTES: The figure depicts the labor supply curves for non-agriculture, $w_{n}\left(L_{n} ; \theta\right)$, and agriculture, $w_{a}\left(L_{n} ; \theta\right)$, respectively. Equilibria are defined by the intersection of the two curves. The arrows illustrate the dynamics of the system when labor follows a Marshallian adjustment process, where migration between sectors takes place at a rate proportional to the current wage differential.

however, in the presence of a permanent wage differential $(\delta>0)$ even under Marshallian dynamics, provided there is a fixed cost of switching sectors. ${ }^{12}$ There will be a range of wage differentials which are insufficient to cover the fixed cost, and this will create a sphere of stability around both of the equilibria depicted in Figure 1.

We can also show local stability of both interior equilibria in the context of a fully specified migration model, based upon rational and forward-looking decisions. To do this, we build on an insight of Howitt and McAfee (1988). Local stability of the first interior equilibria can be obtained when, in addition to the positive externality emphasized above, a small 'crowding diseconomy' is introduced. The crowding diseconomy means that the cost of intersectoral labor migration is increasing in non-agricultural employment. This can be thought of as a simple way to capture a plethora of negative external effects associated with industrialization and urbanization - higher housing costs, increased commuting times, lower environmental quality - that could make cities, and therefore non-agricultural em-

\footnotetext{
${ }^{12}$ We are grateful to Michael Kremer for this observation.
} 
ployment, less attractive as industrialization proceeds. ${ }^{13}$

Since the details of our stability analysis are not essential to grasping the main ideas of the paper - although essential to making them rigorous - we leave a full treatment to Appendix 1. We should note, however, that an explicit specification for the intersectoral labor migration process tends to imply that the equilibrium wage gap, $\delta$, is endogenously determined. Since allowing for this would lessen the ease and transparency of the calibration exercise, we will choose to calibrate the simpler model based on a fixed wage ratio. The approximations involved are unlikely to be important. Our informal experimentation suggests that the results are robust to extending the model to include an endogenous wage gap, driven by a specific migration process.

We should also note the relevance of recent work on equilibrium 'robustness' in a stochastic context. Frankel and Pauzner (2000) analyze a two sector model with increasing returns, based on Matsuyama (1991), in which opportunities to migrate arrive as a Poisson process. They show that if the relative payoff to working in a particular sector is stochastic, the multiplicity property may be eliminated, given certain properties of the sequence of shocks. They also note, however, that this conclusion has not been established for more general migration processes. A similar consideration applies to the work of Herrendorf et al. (1999), who show that sufficient heterogeneity of agents will lead to uniqueness in models like that of Matsuyama (1991). These are all important contributions, but since their generality is not yet clear, we think it remains of great interest to study models that retain the multiplicity property.

Another result in the multiplicity literature is that the introduction of persistent noise into a deterministic system of differential equations typically leads to a refinement in the set of observable equilibria (Foster and Young 1990). Often, one of the deterministic equilibria will be more robust to persistent perturbation than others, suggesting it is more likely to be observed in the long run. At first glance, this appears to cast some doubt on the empirical relevance of multiplicity. The ergodicity introduced by adding noise to a dynamic system, however, is essentially an asymptotic result, especially if the noise in the system is small relative to the deterministic flow. Again, we do not see this argument as general enough to rule out all consideration of multiple equilibria, and even a multiplicity result based on deterministic dynamics retains considerable interest.

\footnotetext{
${ }^{13}$ The interaction of agglomeration economies and crowding diseconomies in the determination of city size is one theme in the new economic geography. See Fujita, Krugman and Venables (1999).
} 


\section{Calibration strategy}

This section now describes our strategy for calibrating the model. Throughout, we will use $a$ to denote agriculture's share of employment, as observed in the data, and $s$ to denote agriculture's share of output, again as observed in the data.

As with many applications of calibration, we assume that we observe the world in equilibrium. More specifically, we assume that the employment and output shares observed in our data correspond to one of the possible equilibrium allocations. The innovative aspect of our approach is that we can then solve for alternative equilibrium allocations in a way that greatly restricts the need for parameter assumptions and data, and thus makes the calibration exercise relatively straightforward and transparent. Although the assumption that we observe the world in equilibrium is a strong one, we have experimented with calibration methods that allow for simple forms of disequilibrium, and our results are generally robust to these alternative assumptions.

Given the observed sectoral structure, we use the assumption of intersectoral capital mobility to solve for the sectoral allocations of capital that are compatible with equilibrium. This allows us to reduce the equilibrium conditions (6) and (7) to a single non-linear equation. Given our assumption that the observed data correspond to one equilibrium solution, this equation depends upon only the technology parameters $(\lambda, \gamma, \alpha, \beta)$ and the agricultural output and employment shares. We can then solve this equation numerically to identify all those labor allocations that satisfy the requirements for equilibrium. These solutions will include, by construction, the observed equilibrium allocation, but also any additional allocations consistent with equilibrium.

The key advantage of our approach is that it circumvents the need for data on such hard-to-measure variables as the capital stock, total employment and sectoral productivity levels. Initially this may seem counter-intuitive, but we can briefly illustrate the underlying principle by returning to the simple one-factor model described at the start of section 2. We indicated that, in the simple model, any interior equilibrium allocation of labor (with agricultural employment share $a$ ) must satisfy:

$$
a^{1-\phi}(1-a)^{\lambda}=\phi\left(\frac{A_{a}}{A_{n}}\right) L^{\phi-1-\lambda}
$$

Denote the left-hand side as $g($.$) . Any other equilibrium allocation (which we$ denote as $b$ ) must satisfy an equation of the same form:

$$
b^{1-\phi}(1-b)^{\lambda}=\phi\left(\frac{A_{a}}{A_{n}}\right) L^{\phi-1-\lambda}
$$


Combining the above two equations means that we can write an equation directly relating the observed employment share, $a$, to the alternative equilibrium allocation, $b$ :

$$
g(a)=g(b)
$$

Hence we do not need to know anything about $A_{a}, A_{n}$, or $L$ to derive the alternative equilibrium allocation of labor. Instead, all we need to know is the form of the equation $g($.$) and the value of the employment share found in the data, a$.

This principle carries over directly to the more complex model that forms the basis for our calibration, and to which we now return. As before, we seek to reduce the theoretical model to one equation and one unknown, where the unknown is the alternative solution for an equilibrium employment share, $b$, given the observed employment share, $a$. Appendix 2 shows that our model implies:

$$
\begin{aligned}
g(a) & =g(b) \\
\text { where } g(q) & =q^{\beta}(1-q)^{\lambda}\left[1-q\left(1-\frac{\alpha}{\gamma} \frac{s}{1-s} \frac{1-a}{a}\right)\right]^{\alpha-\gamma(1+\lambda)}
\end{aligned}
$$

Appendix 2 also shows that, under the parameter restriction

$$
\gamma(1+\lambda)-\lambda<\alpha<\gamma \frac{a}{1-a} \frac{1-s}{s}
$$

there will almost always be two solutions to (9). ${ }^{14}$ One of these solutions will be the observed agricultural employment share, $a$. The other solution will be the other possible equilibrium allocation of labor, $b$.

How can we distinguish whether a given country is in a low output or high output equilibrium? The most obvious method is to solve (9) numerically and compare the alternative solution, $b$, with the observed employment share, $a$. Appendix 2 derives another method, assuming that the parameter restriction above holds. The method is based on a comparison between the assumed value of the externality parameter, $\lambda$, and a critical value $\lambda^{*}$ defined as:

$$
\lambda^{*}=\frac{a(\gamma-\alpha)+\beta(1-a)-(\gamma-\alpha-\beta)(\alpha / \gamma)(1-a)\left(\frac{s}{1-s}\right)}{a(1-\gamma)+\alpha\left(\frac{s}{1-s}\right)\left[1+a\left(\frac{1-\gamma}{\gamma}\right)\right]}
$$

\footnotetext{
${ }^{14}$ Our parameter choices, to be discussed later, will imply that the restriction is satisfied for almost all of the countries in our data set.
} 
This critical value is specific to each country, since it varies with the employment and output shares ( $a$ and $s$ ). A country for which $\lambda<\lambda^{*}$ is in its high output equilibrium. Conversely, $\lambda>\lambda^{*}$ corresponds to a low output equilibrium. If $\lambda=\lambda^{*}$, a knife-edge case, there is only one equilibrium.

The number of countries found to be in a low output equilibrium will vary positively with the assumed extent of increasing returns (captured by $\lambda$ ). The intuition for this is straightforward. The stronger the external effect, the more worthwhile it is to allocate labor to the non-agricultural sector, other things equal. Hence, as $\lambda$ increases, a 'good' equilibrium will correspond to a greater proportion of labor allocated to non-agriculture. Loosely speaking, when the externality parameter takes relatively high values, there are fewer countries for which the observed allocation of labor to non-agriculture is sufficiently extensive for the country to be in a high output equilibrium. We can make this statement more rigorous by noting that our condition for a high output equilibrium, $\lambda<\lambda^{*}$, can be rewritten as a condition on the observed employment share of agriculture, $a<a^{*}$ where

$$
a^{*}=\frac{\beta+\frac{\alpha}{\gamma} \frac{s}{1-s}[\alpha+\beta-\gamma(1+\lambda)]}{\left(1+\frac{\alpha}{\gamma} \frac{s}{1-s}\right)[\alpha+\beta+\lambda-\gamma(1+\lambda)]}
$$

As the externality parameter $\lambda$ increases, the country-specific threshold $a^{*}$ will fall for each country, and hence there will be fewer countries for which the agricultural employment share is low enough to indicate a high output equilibrium.

As well as assigning countries to equilibria, our framework allows us to compute the ratio of output in the alternative equilibrium to that in the current equilibrium. Appendix 2 shows that this ratio is equal to:

$$
\begin{aligned}
\Lambda=\frac{Y^{\prime}}{Y} & =\left(\frac{1-b}{1-a}\right)^{(1-\gamma)(1+\lambda)}\left(1-s\left(\frac{a-b}{a(1-b)}\right)\right) \\
& \times\left[\frac{1+\frac{\alpha}{\gamma}\left(\frac{s}{1-s}\right)}{1+\frac{\alpha}{\gamma}\left(\frac{s}{1-s}\right)\left(\frac{1-a}{a}\right)\left(\frac{b}{1-b}\right)}\right]^{\gamma(1+\lambda)}
\end{aligned}
$$

As this equation makes clear, one advantage of the simplicity of our model is that we can quantify the output effects of equilibrium switching very easily. We require only data on the agricultural output and employment shares, combined with a small number of parameter assumptions. 


\section{Data and assumptions}

In this section, we briefly describe the data and parameter assumptions that will be required to calibrate the model. In assigning each country to a low or high output equilibrium, we require data on agriculture's share of employment and value added ( $a$ and $s$ in our notation). These data are taken from the World Development Indicators CD-Rom 2000, supplemented with other sources where necessary. We will also use data from Hall and Jones (1999), and data on the stock of agricultural land from the FAO Yearbook, when examining international differences in total factor productivity later in the paper. The full data set is described in more detail in Appendix 3.

For the three technology parameters, we choose $\gamma=0.35, \alpha=0.40$ and $\beta=0.20$. We have based the value for the non-agricultural capital share, $\gamma$, on the aggregate capital share often used in growth accounting (see for example Collins and Bosworth 1996). Our figures for the capital and labor shares in agriculture ( $\alpha$ and $\beta$ ) are similar to those used in the GTAP global trade project described in Hertel (1997), which has drawn together data on factor shares from a variety of countries. We have also examined the factor shares implicit in the Martin and Mitra (2001) estimates of a CRS translog production function for agriculture. Their estimates, based on data from the mid-1960s to the present, yield factor shares similar to those adopted here. Later in the paper we will investigate how the findings vary with alternative choices for $\gamma, \alpha$ and $\beta$.

One partial check that our parameter assumptions are plausible is to consider their implications for the aggregate labor share. The aggregate labor share will be simply the sectoral labor shares weighted by the shares of each sector in output. Since our production functions are Cobb-Douglas and factors receive their marginal products, the aggregate labor share is:

$$
\eta=s(1-\alpha-\beta)+(1-s)(1-\gamma)
$$

In our data set, the value of the agricultural output share, $s$, ranges from $0.3 \%$ to $69.3 \%$, with a median of $15.7 \%$. This implies that the aggregate labor share, under our parameter assumptions, will vary between around $48 \%$ in the most agricultural countries to around $65 \%$ in the least agricultural, with a median of about $61 \%$.

The final parameter to consider is $\lambda$, which captures the strength of the external effect in non-agricultural production. Given its likely importance to the results, we will report calibration results based on a wide range of values. Using data on the manufacturing sector in the US and Europe, Caballero and Lyons (1992) find external economies large enough to be consistent with a value for $\lambda$ of roughly 0.20 to 0.30 . Our view that external economies may be this important is also given some 
support by the empirical work in Backus et al. (1992) for a cross-section of countries between 1970 and 1985. Similarly, the analysis of trade flows by Antweiler and Trefler (2000) suggests that increasing returns play a prominent role in about a third of goods-producing industries. Their evidence is potentially consistent with the presence of industry-wide externalities, although other effects may also be at work.

Overall, however, we should acknowledge that the evidence for strong external effects is mixed. Burnside (1996) argues that much of the existing evidence is unreliable, for a variety of reasons. The discussion in Benhabib and Farmer (1996, pp. 434 - 435) surveys a wide range of estimates of external effects, some of which are smaller than those identified by Caballero and Lyons. This is not necessarily a major concern for the present paper, however. Benhabib and Farmer note that aggregation is likely to be associated with stronger increasing returns than found in some of the more disaggregated studies they discuss. More fundamentally, one of the main contributions of the analysis below is to show that even low values for $\lambda$ can generate interesting results.

\section{Multiple equilibria: some basic welfare results}

We now calibrate the model for each of 127 countries as observed in 1988, where the sample is that of Hall and Jones (1999). ${ }^{15}$ Under the maintained assumptions of our model, we can derive both of the possible equilibrium allocations of labor, where two exist. We can infer the nature of a country's equilibrium, low output or high output, and calculate the ratio of output in the high equilibrium to that in the low. We can also assess the potential contribution of multiplicity to international variation in output levels, and explore the implications of the model for the world distribution of income.

In our first set of results, we directly address the question posed in the title of our paper: how much of the international variation in output per worker levels can multiple equilibria explain? To answer this question, we compute summary measures of the cross-country inequality in output per worker. We use inequality measures that are decomposable, so that after dividing our sample of countries into two groups, those in a low and those in a high output equilibrium, we can then decompose the sources of inequality into its 'within-group' and 'betweengroup' components. Note that the assignment of countries to one group or the other, and hence the inequality decomposition, will vary with the assumed degree of increasing returns in non-agriculture.

\footnotetext{
${ }^{15}$ All the calibration experiments were implemented using a program written in Mathematica that is available from the authors on request.
} 
We carry out the inequality decompositions based on two different summary measures of inequality in output per worker. The first measure is a decomposable 'Generalized Entropy' index, due to Shorrocks (1980), with a parameter value of 2. This measure is equal to one-half of the coefficient of variation squared, and so has a simple relation to the variance. The second measure we use is the familiar Theil index of inequality.

These two decompositions are reported in columns (1) and (2) of Table 1, for five different values of $\lambda$. The within-group fraction, corresponding to the proportion of inequality due to the within-group dispersion in the data, is denoted $\frac{W}{I}(\%)$. The between-group fraction, corresponding to the proportion of overall inequality due to differences in income levels between those countries in a low output equilibrium and those in a high output one, is denoted $\frac{B}{I}(\%)$. The between-group component provides an upper bound on the extent of the cross-country inequality in output per worker that might be attributed to multiple equilibria.

The results from this exercise are quite dramatic. For the highest values of $\lambda$ that we examine, we can assign more than half of the inequality in living standards to differences in output levels between those countries in a low output equilibrium and those in a high output one. Even for a value of $\lambda$ as low as 0.05 , our inequality decompositions assign 18 to 28 percent of international inequality to between-group differences.

It is essential to note, however, that income levels may vary across low and high equilibrium countries for reasons other than the low or high nature of their current equilibrium. Countries in a low output equilibrium will typically have other characteristics that lead to low output per worker. In this case our decomposition technique provides only an upper bound on the variation in the cross-country data due to multiple equilibria.

To address this problem, column (3) reports an alternative experiment. First, we compute the variance in the logarithm of output per worker across countries. Next, we 'force' all countries in a low output equilibrium into their alternative, high output equilibrium, calculate the associated increase in output, and then recalculate the variance for this hypothetical or counterfactual distribution. We can then examine the ratio of the two variances, to estimate the reduction in cross-country variation in living standards that we would observe if all countries were to switch to their high output equilibrium.

Even under this new approach, for a value of $\lambda$ of 0.20 we can explain around two-fifths of the international variance in log output per worker, simply by appealing to multiplicity. Note that in contrast to our first approach, this method probably underestimates the amount of variation due to multiple equilibria. This is because it ignores some dynamic or general equilibrium effects that might follow an equilibrium switch, like capital accumulation and increases in schooling. 


\begin{tabular}{lrlrlc}
\hline & \multicolumn{2}{c}{$(1)$} & \multicolumn{2}{c}{$(2)$} & $(3)$ \\
& $I=\frac{1}{2} C V^{2}=0.408$ & $I=$ Theil $=0.389$ & $1-\frac{\operatorname{Var}\left(\ln y^{H I G H}\right)}{\operatorname{Var}\left(\ln y^{A C T U A L}\right)}$ \\
& $\frac{W}{I}(\%)$ & $\frac{B}{I}(\%)$ & $\frac{W}{I}(\%)$ & $\frac{B}{I}(\%)$ & $(\%)$ \\
\hline$\lambda=0.05$ & 81.9 & 18.1 & 72.0 & 28.0 & 0.146 \\
$\lambda=0.10$ & 70.5 & 29.5 & 57.5 & 42.5 & 0.253 \\
$\lambda=0.20$ & 61.4 & 38.6 & 49.9 & 50.1 & 0.393 \\
$\lambda=0.30$ & 53.9 & 46.1 & 44.7 & 55.3 & 0.481 \\
$\lambda=0.50$ & 45.9 & 54.1 & 39.9 & 60.1 & 0.593 \\
\hline
\end{tabular}

Table 1: Multiplicity AND THE Dispersion of InCOME LEVELS

NOTES: Columns (1) and (2) report inequality decompositions where the level of output per worker is partitioned into a within-group component $\left(\frac{W}{I}(\%)\right)$ and a between-group component $\left(\frac{B}{I}(\%)\right)$. The two comparison groups are low equilibrium and high equilibrium countries respectively. The decomposition is performed using a 'Generalized Entropy' measure for inequality with a parameter equal to 2 (see Mookherjee and Shorrocks 1982) and for the Theil coefficient. The former measure is identical to one-half the cofficient of variation squared and thus has a familiar variance interpretation. Column (3) takes a different approach to quantifying the impact of multiple equilibria on the world distribution of income and reports one minus the ratio of the hypothetical variance in the log of output per worker that would be observed if all countries were in their high output equilibrium over the actual variance. 
Next, we ask a closely related question. What would the world distribution of income look like, if all countries were in a high output equilibrium? It has been suggested by Quah $(1993,1997)$ and Jones $(1997)$ that the world income distribution may be bimodal, or at least tending towards that form. Calibration allows us to investigate the extent to which this feature might be attributed to multiplicity. The exercise should be seen as only illustrative, especially since for simplicity, we do not model the general equilibrium effects that operate at the level of the world as a whole. ${ }^{16}$ Nevertheless, examining the impact of multiplicity on the world income distribution may be informative, and is particularly useful in allowing us to indicate where in the distribution 'poverty traps' may have the greatest impact.

Figure 2 plots kernel density estimates for the actual distribution of output per worker (the solid line) and for a selection of our hypothetical distributions, generated by placing all countries in their high output equilibrium. As is apparent from the figure, the 'poverty traps' implied by our model are most frequently found among the very poorest countries within the distribution. Our particular model appears best suited to explaining income differences between the least developed countries and middle income countries, rather than differences between middle income countries and the industrialized nations. To put this in more concrete terms, the model we have calibrated may offer some partial insight into why incomes in Africa are low, but it has much less to say about the current positions of Latin American and East Asian economies relative to the industrialized countries. This may or may not be a general feature of calibrated models with multiple equilibria, but it does show one respect in which calibration can help to explore the properties of these models.

A remaining question is the size of the output effects associated with a switch between equilibria. It is clear that, to be of practical interest, a theoretical model of multiplicity should yield equilibria that greatly differ in terms of output per worker. Table 2 offers some insight into this question for our model. We consider five cases, again corresponding to different values of the externality parameter $\lambda$.

We focus on columns (1) and (2) initially. They report the number of countries found to be in a low and high output equilibrium respectively. Even with a limited role for the agglomeration externality $(\lambda=0.10)$ we find that roughly a quarter of the countries in our sample are found to be in the low output equilibrium. With a stronger external effect, the proportion of countries assigned to the low output equilibrium increases, as predicted by the analysis above.

In column (3), we report the mean and median output ratio across the high and low equilibria for countries found to be in a low output equilibrium. Column (4)

\footnotetext{
${ }^{16}$ The simplification here is to treat world prices as fixed throughout. In principle, we should allow world prices to vary as patterns of sectoral structure change.
} 


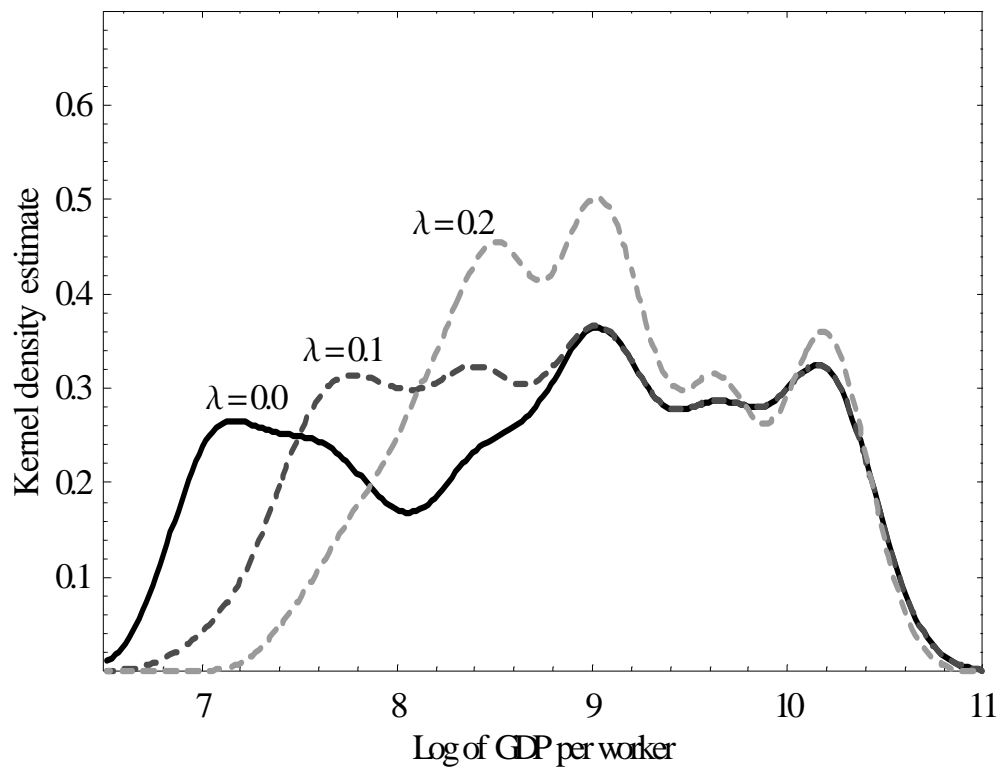

Figure 2: Multiplicity AND THE World Distribution of INCOME (DENSITY ESTIMATES)

NOTES: This figure graphs kernel density estimates for the actual distribution of the logarithm of output per worker across countries and for the hypothetical distribution that would occur if all countries were in their high output equilibrium for the case where $\lambda$ equals 0.10 and 0.20. Bandwidth selection is by the plug-in method of Sheather and Jones (1991).

\begin{tabular}{|c|c|c|c|c|}
\hline & $\begin{array}{c}(1) \\
\text { \# of counties } \\
\text { in low }(\%)\end{array}$ & $\begin{array}{c}(2) \\
\text { \# of counties } \\
\text { in high }(\%)\end{array}$ & $\begin{array}{c}(3) \\
\text { Mean/Median } \\
\left(y^{H} / y^{L}\right) \\
\text {-"low" - }\end{array}$ & $\begin{array}{c}\text { (4) } \\
\text { Mean/Median } \\
\left(y^{H} / y^{L}\right) \\
\text {-"high"- }\end{array}$ \\
\hline$\lambda=0.05$ & $21 \quad(16.5 \%)$ & $106 \quad(83.5 \%)$ & $1.55 / 1.31$ & $1.85 / 1.79$ \\
\hline$\lambda=0.10$ & $33(26.0 \%)$ & $94 \quad(74.0 \%)$ & $1.70 / 1.53$ & $1.82 / 1.72$ \\
\hline$\lambda=0.20$ & $44 \quad(34.6 \%)$ & $83 \quad(65.4 \%)$ & $2.03 / 1.70$ & $1.72 / 1.62$ \\
\hline$\lambda=0.30$ & $56 \quad(44.1 \%)$ & $71 \quad(55.9 \%)$ & $2.20 / 1.74$ & $1.68 / 1.53$ \\
\hline$\lambda=0.50$ & $67 \quad(52.8 \%)$ & $60 \quad(47.2 \%)$ & $2.69 / 2.11$ & $1.57 / 1.47$ \\
\hline
\end{tabular}

Table 2: The Welfare ImPliCATIONS OF Multiple EQuilibria

NOTES: The table reports the distribution of equilibrium assignments for various values of $\lambda$. Columns (3) and (4) report the mean and median inter-equilibrium output ratios for countries assigned to low and high output equilibria respectively. 
does the same for countries found to be in a high output equilibrium. From the table, we can see that if low equilibrium economies switched to their higher equilibrium (column 3 ) then output per head would rise by a factor roughly between 1.5 and 2.7, for the values of the externality parameter that we consider here. ${ }^{17}$ The median output gain is similar to the mean, so output gains of this magnitude are not unrepresentative.

It is worth noting that the output gains reported in column (3) are likely to be underestimates. In analyzing the output effect of an equilibrium switch, we are holding everything else constant. We would find higher output gains if we were to make physical capital endogenous. Similarly, growing expenditure on education could also play a role in magnifying the effects of an equilibrium switch.

While these are substantial output gains, they again underline the conclusion implicit in Figure 2 above. Our model seems to have the greatest power in explaining differences between the low end and the middle of the distribution. This conclusion is consistent with the idea that poverty trap models are best at illuminating the transition to 'modern economic growth' (in the sense of Kuznets 1966) rather than the differences between, say, the US and middle income countries.

\section{Multiple equilibria and aggregate TFP}

In this section, we explore the implications of our model for understanding international differences in total factor productivity (TFP). The likely extent of these differences is one of the most debated topics in recent work on growth. Mankiw, Romer and Weil (1992) initiated this debate by arguing that aggregate TFP should be broadly similar across countries, since it should be possible to transfer technology across national borders at low cost. More recently, several influential papers have criticized this view, claiming that substantial differences in aggregate TFP are needed to explain the observed variation in output per worker across countries (Hall and Jones 1999, Klenow and Rodriguez-Claré 1997, and Prescott 1998). Subsequent research has consequently focused on developing coherent theoretical explanations for these TFP differences (see for example Acemoglu and Zilibotti 2001, Basu and Weil 1998, and Caselli and Coleman 2000).

In this section, we will show that our approach may have important implications for this debate. In our framework, it is possible that much of the measured international variation in aggregate TFP may reflect the presence of multiple equilibria. Consider two countries identical in all respects, with the exception that one is in a low output equilibrium while the other is in a high output equilibrium. The

\footnotetext{
${ }^{17}$ There are two influences on this output gain: the external effect, and the differential in the marginal product of labor across sectors. We will examine this issue further in section 8 below.
} 
'levels accounting' of, for example, Hall and Jones (1999) will identify a difference in total factor productivity across the two countries. This TFP difference may be incorrectly attributed to a difference in technology, when in fact it arises through multiple equilibria.

To investigate this further, we will compare the cross country dispersion of a standard measure of aggregate TFP with the dispersion that would be observed if all countries were in their high output equilibrium. ${ }^{18}$ We will show that a model with multiple equilibria, of the kind analyzed here, can indeed account for a significant fraction of the international variation in productivity.

For comparison with previous work on TFP differences, we will take into account international differences in human capital. Our adjustments are identical in form to those of Hall and Jones (1999). The basic idea is to construct units of 'effective' labor that are compatible with the Mincerian wage regressions of labor economics. We define $h=e^{\phi(E)}$, where $\phi(E)$ is the efficiency of a worker with $E$ years of schooling relative to a worker with no schooling. The form of $\phi($.$) is$ piecewise linear as constructed and parameterized by Hall and Jones (1999). For simplicity, we assume that workers in agriculture and non-agriculture are equally well educated, so the total amount of human capital-augmented labor in sector $i$ is then $h L_{i}$, where $i=n, a$.

We calculate aggregate TFP using Törnqvist comparisons between individual countries and the world mean (Christensen, Cummings and Jorgenson 1981). To make these comparisons, we use the aggregate factor shares implied by our model. Let $\eta_{L, i}, \eta_{R, i}$ and $\eta_{K, i}$ be the aggregate income shares for labor, land, and capital in country $i$. Under the assumptions of our model, it is easily shown that these shares are equal to:

$$
\begin{aligned}
\eta_{L, i} & =s_{i}(1-\alpha-\beta)+\left(1-s_{i}\right)(1-\gamma) \\
\eta_{R, i} & =s_{i} \beta \\
\eta_{K, i} & =s_{i} \alpha+\left(1-s_{i}\right) \gamma
\end{aligned}
$$

where $s_{i}$ is agriculture's share of output in country $i$. We then compute a measure of the logarithm of aggregate TFP relative to its world mean:

\footnotetext{
${ }^{18}$ Although our two sector model allows a more sophisticated decomposition of output differences, based on measurement of productivity at the level of the two sectors, here we concentrate on the aggregate decompositions favored by most researchers.
} 


\begin{tabular}{lcccccc}
\hline & \multirow{2}{*}{$\begin{array}{c}(2) \\
\text { \% Variance from } \\
\text { Multiplicity }\end{array}$} & $\bar{\eta}_{L}$ & $\bar{\eta}_{D}$ & $\bar{\eta}_{K}$ \\
\hline $\operatorname{TFP}($ Actual $)$ & $V\left(\log T F P_{i}-\overline{\log T F P}\right)$ & - & 0.600 & 0.040 & 0.360 \\
$\operatorname{TFP}(\lambda=0.05)$ & 0.234 & 14.5 & 0.608 & 0.034 & 0.358 \\
$\operatorname{TFP}(\lambda=0.10)$ & 0.200 & 24.1 & 0.614 & 0.029 & 0.357 \\
$\operatorname{TFP}(\lambda=0.20)$ & 0.177 & 29.1 & 0.622 & 0.022 & 0.356 \\
$\operatorname{TFP}(\lambda=0.30)$ & 0.166 & 27.6 & 0.628 & 0.018 & 0.354 \\
$\operatorname{TFP}(\lambda=0.50)$ & 0.169 & 13.1 & 0.635 & 0.012 & 0.353 \\
\hline
\end{tabular}

Table 3: Multiple Equilibria And the World Distribution of TFP

NOTES: The table lists the variance of the log of aggregate TFP (Column (1)). TFP is calculated using Christensen, Cummings and Jorgenson's (1981) method for the actual data and for the hypothetical data created by placing all countries in their high output equilibrium. The percentage of the variance due to multiple equilibria (Column (2)) is then calculated as 1 minus the ratio of the hypothetical variance of TFP to the actual variance of TFP. Column (3) reports the average factor shares implied by our model for the actual and hypothetical data.

$$
\begin{aligned}
\log A_{i}-\overline{\log A}= & \log \frac{Y_{i}}{L_{i}}-\overline{\log \frac{Y}{L}}-0.5\left(\eta_{K, i}+\bar{\eta}_{K}\right)\left[\log \frac{K_{i}}{L_{i}}-\overline{\log \frac{K}{L}}\right](17) \\
& -0.5\left(\eta_{R, i}+\bar{\eta}_{R}\right)\left[\log \frac{R_{i}}{L_{i}}-\overline{\log \frac{R}{L}}\right] \\
& -0.5\left(\eta_{L, i}+\bar{\eta}_{L}\right)\left[\log h_{i}-\overline{\log h}\right]
\end{aligned}
$$

where the line over a variable indicates an average over the countries in our sample.

To obtain the counterfactual distribution of TFP, we force all countries into their high output equilibrium, recalculate (14) to (16) using the new sectoral structure of value added, and then recalculate the deviation of country $i$ 's logarithm of TFP from the logarithm of the world mean using equation (17).

Table 3 shows the results for various assumptions about the externality parameter, $\lambda$. According to our model, up to around 30 percent of the observed variation in the logarithm of aggregate TFP can be given a multiple equilibria interpretation. Figure 4 gives a visual depiction of the cross-country distribution of aggregate TFP and the impact of multiple equilibria on this distribution. The solid line is a kernel density estimate for the actual distribution of the logarithm of TFP, while the two dashed lines are density estimates for the hypothetical distributions when $\lambda=0.10$ and $\lambda=0.30$ and all countries are in their high output equilibrium. 


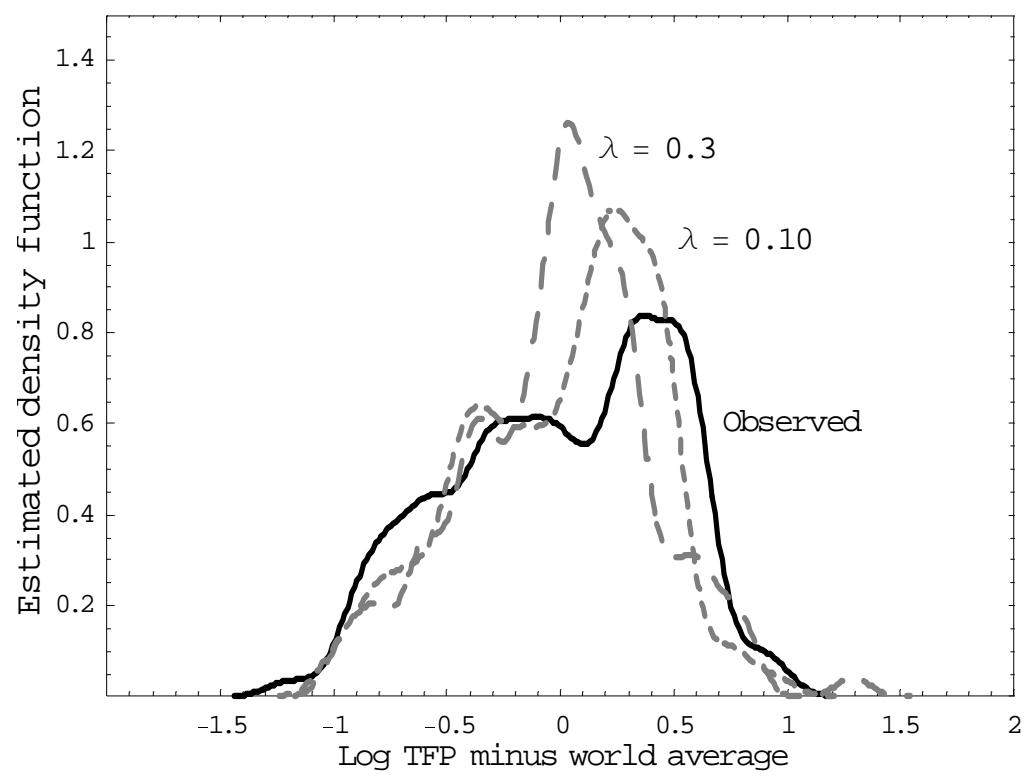

Figure 3: Aggregate TFP Measures

NOTES: Kernel density estimates for the actual distribution of aggregate TFP across countries and a selection of the counterfactuals discussed in the text. Bandwidths were chosen using Sheather and Jones' (1991) plug-in method. The kernel is a univariate standard normal density function.

As is apparent from the figure, allowing for multiple equilibria leads to a tightening of the aggregate TFP distribution. In principle this could be one way to reconcile international TFP differences with the view that technology can be transferred easily across national borders. Yet even for large values of $\lambda$, there is sufficient remaining variation in TFP that this 'public good' view of technology continues to look slightly problematic.

We end this section by noting that we could also use our framework to investigate productivity measures at the level of sectors ( $A_{n}$ and $A_{a}$ in our notation). Given the structure of our model, these are the most appropriate measures of the level of 'technology' used by a given country. One attractive feature of our calibration exercise is that we can easily compute an estimate of productivity for both the agricultural and non-agricultural sectors, and we are exploring this in ongoing research. 


\section{Equilibrium switching}

One way to establish the relevance of 'poverty trap' models would be to isolate events in the data that could represent a switch between equilibria. In this section, we show how calibration can be used for this purpose. We also provide a speculative analysis of the future changes in the world distribution of income that are implied by our framework.

By calibrating our model for two points in time - we choose 1965 and 1988 for data availability reasons - we can determine which countries exhibited patterns of structural change over the period that are consistent with a shift from a low output equilibrium to a high output one. The model indicates that a switch has occurred when the 1988 values of the employment and output shares imply an equilibrium different in nature (high output or low output) from that of $1965 .{ }^{19}$

Table 4 lists a few selected countries by major world region for each of the observed events in the data: (1) a movement from the low to high output equilibrium over the 1965 to 1988 period, (2) staying in the low output equilibrium over the period, and (3) staying in the high output equilibrium. A fourth possibility, movement from a high to low equilibrium, is not observed in our sample, a result which we discuss further below.

Even under the relatively conservative assumption that $\lambda=0.10$ our model can account for some interesting features of the data. First, the few African 'success stories' can be given an equilibrium switching interpretation, as can the growth experiences of parts of southern Asia. For this parameter assumption, however, our model says little about the causes of the East Asian growth miracle. The calibration exercise indicates that all of this region's fast growing economies - with the exception of Indonesia - were already in their high output equilibrium in 1965.

This result is, perhaps unsurprisingly, sensitive to our choice for $\lambda$. Table 5 provides a similar list of countries for the case where $\lambda=0.30$. Under this parameter assumption we are able to interpret the East Asian miracle as equilibrium switching, with the exception of the growth performances of the two city states, Hong Kong and Singapore. We are also able to explain some of the more robust Latin American growth performances, including that of Brazil.

In addition, this exercise allows us to compute a transition matrix for movement between the low and high output equilibria. Using this transition matrix we can examine the possible evolution of the world distribution of income in the long run, in a way familiar from previous work on this topic (Quah 1993, Jones 1997, and

\footnotetext{
${ }^{19}$ Note that simply looking at the change in the employment share will not work. Over time capital accumulation and technical progress have taken place, so even if the change in the employment share appears to imply an equilibrium switch, this may not be the case. Our earlier analysis shows that the current output share is also needed to infer the nature of a country's equilibrium.
} 


\begin{tabular}{cccc}
\hline & LOW TO HIGH & LOW TO LOW & HIGH TO HIGH \\
\hline & Latin America & Latin America & Latin America \\
& Honduras & Haiti & Argentina \\
& - & - & Chile \\
& - & - & Uruguay \\
Africa & Africa & Africa \\
COUNTRIES & Bostwana & Burkina Faso & Lesotho \\
& Cote d'Ivoire & Congo (fmr Zaire) & South Africa \\
& Gabon & Ethiopia & Mauritius \\
& Asia & Asia & Asia \\
& India & Bangladesh & Hong Kong \\
& Indonesia & Myanmar (Burma) & Singapore \\
& - & Nepal & Japan \\
& Europe & Europe & Europe \\
Turkey & - & France \\
- & - & Germany \\
& - & - & United Kingdom \\
\hline
\end{tabular}

Table 4: EQUILBRIUM DYNAMICS, 1965 TO $1988(\lambda=0.10)$

NOTES: The model is calibrated in 1965 and 1988 for $\lambda=0.10$ and equilibrium assignments for individual countries are compared across the two points in time to derive the above table. No countries went from their high equilibrium to their low equilibrium during the sample period. Unfortunately the value added data cannot be adjusted to net out mining output in 1965, therefore unadjusted data is used across both periods. We are able to do the two point calibration for 121 of the 127 countries in the main sample. 


\begin{tabular}{cccc}
\hline & LOW TO HIGH & LOW TO LOW & HIGH TO HIGH \\
\hline & Latin America & Latin America & Latin America \\
& Brazil & Bolivia & Argentina \\
Costa Rica & Guatemala & Chile \\
Mexico & Haiti & Uruguay \\
& Africa & Africa & Africa \\
Swaziland & Burkina Faso & Lesotho \\
& - & Congo (fmr Zaire) & South Africa \\
COUNTRIES & Ethiopia & Mauritius \\
& - & Asia & Asia \\
& Asia & Bangladesh & Hong Kong \\
& Korea & India & Singapore \\
Malaysia & Nepal & Japan \\
& Taiwan & Europe & Europe \\
Europe & Turkey & France \\
Greece & - & Germany \\
Poland & - & United Kingdom \\
\hline
\end{tabular}

Table 5: EQUILBRIUM DYNAMICS, 1965 TO $1988(\lambda=0.30)$

NOTES: The model is calibrated in 1965 and 1988 for $\lambda=0.30$. For other notes see Table 4. 


\begin{tabular}{ccccc}
\hline \multicolumn{3}{c}{$\lambda=0.10$} & \multicolumn{2}{c}{$\lambda=0.30$} \\
\hline \multirow{2}{*}{ LOW } & LOW & HIGH & LOW & HIGH \\
HIGH & 0.689 & 0.311 & 0.667 & 0.333 \\
& 0.000 & 1.000 & 0.000 & 1.000 \\
\hline
\end{tabular}

Table 6: Transition MATRIX FOR EQUILIBRIUM SWITCHING

NOTES: Transition matrix generated from the two point (1965 and 1988) calibration (n $=121$ ). Note that the high output equilibrium appears to be an absorbing state.

Kremer, Onatski and Stock 2001).

Table 6 reports our calculation of the transition matrix for movements between equilibria. The calculation is based on observed equilibrium switches between 1965 and 1988, again for the cases where $\lambda$ is assumed to be 0.10 and 0.30 . There are two properties of the calculated matrix that are worthy of note. First, the low output equilibrium is relatively persistent: the probability of exiting over more than twenty years is only about $30 \%$ for both the cases considered. Second, the high output equilibrium appears to be an absorbing state. Once a country enters its high output equilibrium it stays there permanently. This second feature of our results is similar to the finding of Kremer, Onatski and Stock (2001) that departures from the upper regions of the world distribution of income are relatively rare. For those interested in the possibility of multiplicity, such findings are of especial interest in their suggestion that equilibrium selection may rest on more than expectations.

Table 7 reports the fraction of countries in their low and high output equilibria in 1965 and 1988, and uses our transition matrix to project these fractions into the future. Our results suggest that, again for the case of $\lambda=0.10$, in 1965 almost 40 percent of the world's countries were in a low output equilibrium; by 1988 this had fallen to a quarter. In principle, the transition matrix implies that by the middle of this century, less then 10 percent of the world's economies will remain in their low output equilibrium.

These calculations are, of course, subject to a number of important caveats even if we make the heroic assumption that our model is a good approximation to reality. The projections rely on the past transition process being a good guide to the future. There are many reasons for skepticism here. The probability that an individual country makes an equilibrium switch is likely to be a function of that country's characteristics. This would imply that our forecasts for mid-century are over-optimistic, perhaps wildly so, since countries with the greatest capacity to reach their high output equilibrium will be the ones that have already done so.

Clearly, none of these specific results should be taken too seriously. Nevertheless, they are indicative of how calibration could inform the debate on the potential 


\begin{tabular}{|c|c|c|c|c|c|c|c|}
\hline & \multicolumn{7}{|c|}{ THE EVOLUTION OF THE WORLD DISTRIBUTION OF INCOME } \\
\hline \multirow{3}{*}{$\lambda=0.10$} & & 1965 & 1988 & 2011 & 2034 & 2057 & ERGODIC \\
\hline & Percent in Low & 37.2 & 25.6 & 17.6 & 12.2 & 8.4 & 0.0 \\
\hline & Percent in High & 62.8 & 74.4 & 82.4 & 87.8 & 91.6 & 100.0 \\
\hline \multirow{3}{*}{$\lambda=0.30$} & & 1965 & 1988 & 2011 & 2034 & 2057 & ERGODIC \\
\hline & Percent in Low & 64.5 & 43.0 & 28.7 & 19.1 & 12.7 & 0.0 \\
\hline & Percent in High & 35.5 & 57.0 & 71.3 & 80.9 & 87.3 & 100.0 \\
\hline
\end{tabular}

Table 7: The Distribution of Countries Across Equilibria

NOTES: The world distribution of countries across the low and high output equilibria. The percentages for 1965 and 1988 are "actuals" while the other values are derived by exponentiating the transition matrix.

relevance of multiplicity for understanding the growth process. In particular, calibration helps to identify the countries for which a multiple equilibrium interpretation is most likely to have some plausibility, and so can help in selecting individual cases for further study. The exercise also confirms that more informal discussions of the role of multiple equilibria, as in the work of Rodrik $(1995,1996)$ on the East Asian Miracle, are potentially consistent with the data under the maintained assumptions of our model.

\section{Sensitivity analysis}

In this section we provide some brief sensitivity analysis, to indicate how particular results are modified by alternative parameter assumptions. The first part of the section investigates how the apparent prevalence of poverty traps will vary with assumptions on the technology parameters $\alpha, \beta, \gamma$ and $\lambda$. The second part of the section will investigate the sensitivity of our results to variation in the marginal product differential across sectors.

We earlier indicated that the assignment of countries to a low output or high output equilibrium can be achieved by comparing the assumed external effect $\lambda$ with a country-specific critical value $\lambda^{*}$, given by:

$$
\lambda^{*}=\frac{a(\gamma-\alpha)+\beta(1-a)-(\gamma-\alpha-\beta)(\alpha / \gamma)(1-a)\left(\frac{s}{1-s}\right)}{a(1-\gamma)+\alpha\left(\frac{s}{1-s}\right)\left[1+a\left(\frac{1-\gamma}{\gamma}\right)\right]}
$$

This critical value for lambda is increasing in the exponent on land, $\beta$, by inspection. That is, the higher the $\beta$ parameter, the higher the critical value for 
each country. This means that there will be fewer economies for which $\lambda>\lambda^{*}$ and so fewer economies will be found to be in a low output equilibrium.

By differentiating $\lambda^{*}$ with respect to $\alpha$ and $\gamma$, it is also possible to establish conditions under which $\lambda^{*}$ is decreasing in $\alpha$ and increasing in $\gamma$. These conditions, however, are functions of the three technology parameters $(\alpha, \beta, \gamma)$ and also the agricultural employment and output shares, $a$ and $s$, and so must be evaluated using the data. The conditions are satisfied for almost every single country in our data set when evaluated at our assumed parameter values, but cannot be assumed to hold more broadly.

For this reason, we investigate the sensitivity of our findings to parameter assumptions using graphical methods. The four panels of Figure 4 show the proportion of countries that are found to be in a low output equilibrium for various configurations of parameters. From the top-right panel, it is clear that the proportion of countries found to be 'trapped' is increasing in $\lambda$ and decreasing in $\beta$, exactly as our theoretical analysis predicts. The other panels show the more complex patterns associated with varying the other technology parameters, $\alpha, \gamma$ and $\lambda$, in each case holding one constant and varying the other two.

The second aspect of our sensitivity analysis is more subtle. Earlier sections of the paper quantified the output gain associated with an equilibrium switch. The size of this output gain depends on the size of the externality parameter, but also on the magnitude of the wage differential across sectors. This marginal product differential reinforces the effect of reallocating labor to non-agriculture, in moving from a low output equilibrium to a high output equilibrium.

One drawback of our simple model is that plausible values for technology parameters yield large intersectoral wage differentials. One probable explanation is that, in reality, the non-agricultural sector makes more intensive use of skilled labor than agriculture. Allowing for this is not straightforward within the framework of this paper, but it does raise the concern that our previous analysis overstates the true extent of marginal product differentials, and therefore overstates the output effects of an equilibrium switch.

In the remainder of this section, we explore the sensitivity of our results to this property of the model. To do this, we use a simple trick that allows lower wage differentials to be considered while retaining our other assumptions. The trick is to assume that a certain fraction of agricultural output, $\epsilon$, is unmeasured in the national accounts. Some agricultural output may be produced for non-marketed household consumption, and so does not appear in the national accounts as either output or factor income. Under various assumptions about the magnitude of $\epsilon$, we adjust agriculture's share in GDP for this mismeasurement, and then recalculate the equilibrium solutions and the associated welfare effects.

An important advantage of this approach is that it has a straightforward effect 

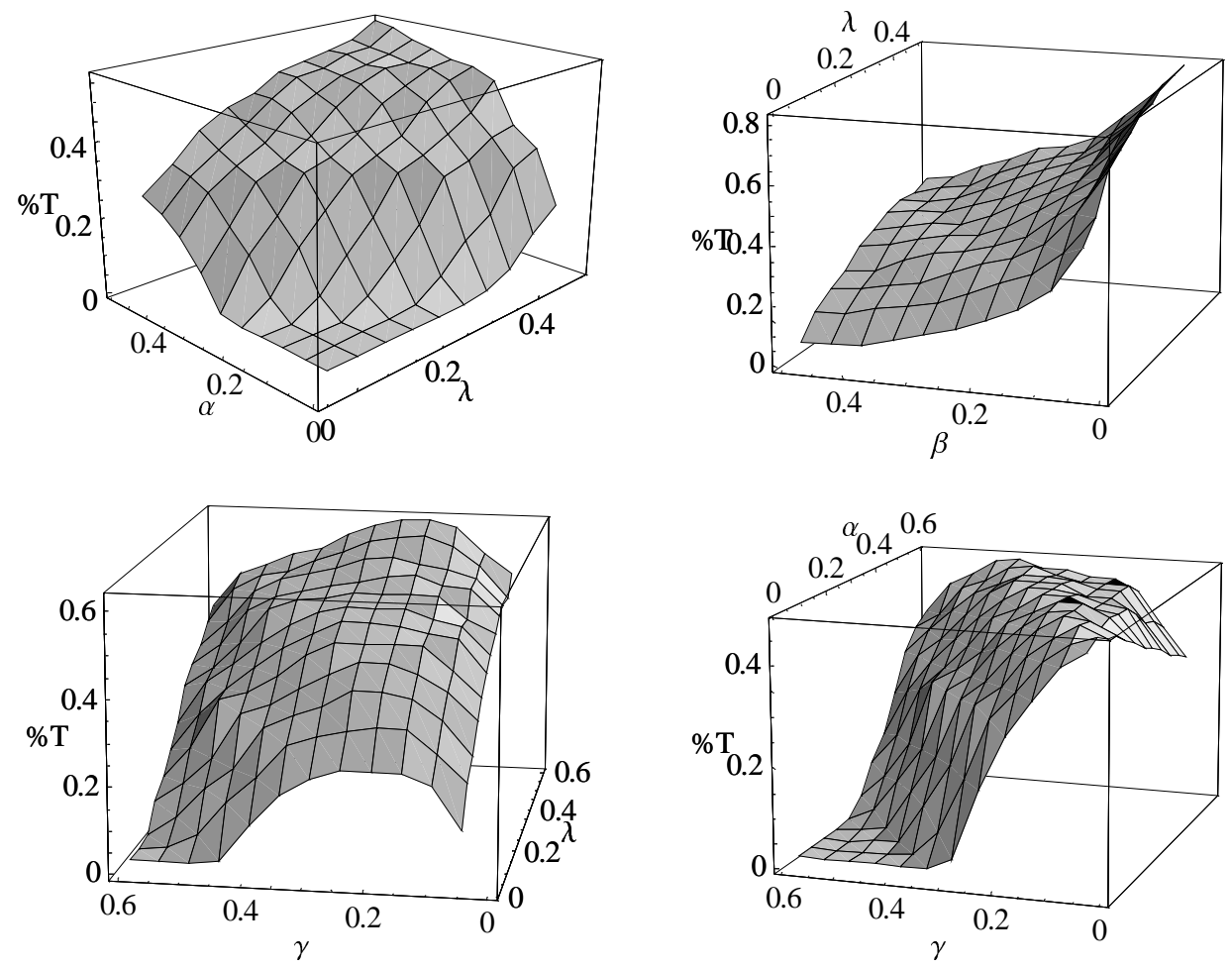

Figure 4: Robustness to DifFERENT PARAMETER ASSUMPTIONS

NOTES: This figure illustrates the importance of our assumptions regarding $\alpha, \beta, \gamma$ and $\lambda$ for equilibrium assignment. Reading across from the top-left: Panel 1: $\gamma$ and $\beta$ held fixed at 0.35 and 0.20. Panel 2: $\gamma$ and $\alpha$ held fixed at 0.35 and 0.40. Panel 3: $\alpha$ and $\beta$ held fixed at 0.40 and 0.20 . Panel $4: \beta$ and $\lambda$ held fixed at 0.20 and 0.30 . 
on the wage differential implicit in our calculations. Since we are using CobbDouglas production functions, marginal products, and hence wages, are proportional to average products. Since assuming $\epsilon=0.5$ implies that 'true' average labour productivity in agriculture is double that in the unadjusted data, it will halve the ratio of wages in non-agriculture to agriculture that is implicit in our calculations.

The adjustments are easily made. We denote true agricultural output as $Y_{a}^{*}$ and measured agricultural output as $Y_{a}=(1-\epsilon) Y_{a}^{*}$. Hence true output is $Y^{*}=$ $Y_{a}^{*}+p Y_{n}$ and measured output is $Y=Y_{a}+p Y_{n}$. The data we have on agricultural output shares correspond to $s=Y_{a} /\left(Y_{a}+p Y_{n}\right)$. We want to calculate the 'true' or adjusted output shares $s^{*}=Y_{a}^{*} /\left(Y_{a}^{*}+p Y_{n}\right)$. It is easy to show that the 'true' share can be expressed as:

$$
s^{*}=\frac{s}{1-\epsilon+s \epsilon}
$$

Using this result, we adjust the output share data for various possible values of $\epsilon$ and then recalculate some of our earlier statistics. The results are shown in Table 8 for the case of $\lambda=0.10$. The quantity of most interest is the output gain in switching between the low and high equilibria. As $\epsilon$ is increased from the benchmark case of accurate measurement $(\epsilon=0)$ the effect of an equilibrium switch on output diminishes, consistent with the reductions in the wage differential that are implicit in these calculations. Yet the reductions in the output gain are relatively modest, implying that our earlier results are not driven simply by large marginal product differentials across sectors. 


\begin{tabular}{|c|c|c|c|c|c|}
\hline & $\begin{array}{c}(1) \\
1-\frac{\operatorname{Var}\left(\ln y^{H I G H}\right)}{\operatorname{Var}\left(\ln y^{A C T U A L}\right)} \\
(\%)\end{array}$ & $\begin{array}{c}(2) \\
\% \\
\text { in low }\end{array}$ & $\begin{array}{c}(3) \\
\% \\
\text { in high }(\%)\end{array}$ & $\begin{array}{c}\text { (4) } \\
y^{H} / y^{L} \\
\text { (Mean) } \\
\text {-"low"- }\end{array}$ & $\begin{array}{c}\text { (5) } \\
y^{H} / y^{L} \\
\text { (Mean) } \\
\text {-"high" - }\end{array}$ \\
\hline$\epsilon=0.00$ & 25.3 & 26.0 & 74.0 & 1.70 & 1.82 \\
\hline$\epsilon=0.10$ & 24.7 & 26.0 & 74.0 & 1.67 & 1.74 \\
\hline$\epsilon=0.20$ & 24.1 & 26.8 & 73.2 & 1.61 & 1.66 \\
\hline$\epsilon=0.30$ & 23.3 & 28.3 & 71.7 & 1.54 & 1.58 \\
\hline$\epsilon=0.40$ & 22.3 & 28.3 & 71.6 & 1.49 & 1.48 \\
\hline$\epsilon=0.50$ & 20.9 & 30.7 & 69.3 & 1.41 & 1.39 \\
\hline
\end{tabular}

Table 8: RobUSTNESS OF MAIN RESULTS TO MIS-MEASURED AGRICULTURAL OUTPUT

NOTES: Column (1) reports the ratio of the hypothetical variance of the log of GDP per worker when all countries are in their high output equilibrium to the actual variance for various assumptions regarding the degree to which agricultural output is undermeasured. Columns (2) and (3) show how equilibrium assignment is affected by mis-measurement, while columns (4) and (5) show how average output gains are affected.

\section{Conclusion}

Although models with multiple equilibria are a popular explanation for the gulf between rich and poor nations, few papers have attempted to investigate the practical implications of such models. In this paper, we have sought to address this omission by using calibration. We take as our starting point one of the simplest models with multiplicity, a two sector model with a sector-specific externality. We have shown how to calibrate such a model in a way that greatly limits the need for parameter assumptions and data. In turn, this means that calibrating the model even for 127 countries is a relatively simple procedure.

This exercise gives rise to a number of interesting findings. Sections 5 and 8 established that, depending on the choice of parameters, a large number of countries might be regarded as in a low output equilibrium, under the maintained assumptions of our model. We also found that multiple equilibria can potentially account for a substantial fraction of the international inequality in output per worker.

The account is by no means a complete one, however. Holding all else constant, a switch to a more productive equilibrium will roughly double output, with the precise figure depending on the strength of the externality. This is a substantial gain, but falls a long way short of explaining the difference between, say, the US and India. To put this another way, if we were to attempt to choose parameters in such a way that we could explain most of the international variation in living stan- 
dards, the model would require an implausibly strong degree of increasing returns in non-agriculture.

We were able to shed additional light on the model's implications by constructing a 'counterfactual' world distribution of income. Our calibration exercise allows us to calculate the output levels that would prevail if all countries were in their high output equilibrium. As we showed in section 5, this makes most difference to the very poorest countries. The particular model we calibrated can explain some of the gap between poor countries and middle income countries, but is much less well suited to explaining the gap between middle income countries and the richest nations.

By calibrating the model for two different points in time, 1965 and 1988, we can also identify events in the data that correspond to equilibrium switching under the maintained assumptions of our model. Thus, calibration may be particularly useful in identifying particular countries where rapid growth might correspond to a switch between two equilibria. We have also been able to clarify the implications of multiplicity for the debate on international differences in total factor productivity.

Inevitably, some of our findings are speculative. The model we have used is a simple one, and the underlying assumptions are strong. One assumption in particular stands out: the quantitative implications of our model crucially depend on the size of the externality parameter. The evidence on the importance of sectorspecific externalities is mixed and, although even small external effects can give rise to interesting findings, the lack of reliable supporting evidence must be seen as a limitation of the approach we have adopted. More generally, although our calibration exercise offers some useful insight into the properties of the model we analyze, it does not provide a formal test of its validity. Nor do we provide an explanation for why countries arrive at particular equilibria. For all these reasons, we are keen to emphasize that our investigation of multiplicity is currently far too preliminary to draw any lessons for policy.

Nevertheless, we think it is intriguing that even a simple model can give rise to such wide-ranging implications. By applying calibration methods, we have learnt a great deal about the potential explanatory power of the model, and its strengths and limitations. Calibration appears to be one of the most promising ways forward for research on multiple equilibria. We hope that future researchers will be encouraged to explore these ideas further, and perhaps to bring richer models to the data.

\section{Appendix 1: Stability analysis}

This appendix outlines a specification for the dynamics which implies that both interior equilibria are locally stable. It also briefly discusses the approximation 
involved in our use of a simpler model for calibration purposes.

In specifying the dynamics, we retain the assumption that capital costlessly moves between sectors to equalize rental rates, but now assume that labor migration is costly. In particular, migration costs are described by a convex cost function, $C\left(\dot{L}_{n}, L_{n}\right)$, where $C_{1}>0, C_{11}>0$, and $C\left(0, L_{n}\right)=0$. Migration costs are also increasing in the total amount of labor employed in non-agricultural production due to crowding diseconomies (i.e., $C_{2}>0$ and $C_{12}>0$ ).

The representative individual chooses the level of migration, $\dot{L}_{n}$, to maximize the present discounted value of income net of migration costs:

$$
V\left(L_{n}\right)=\max _{\left\{\dot{L}_{n}\right\}} \int_{\tau=t}^{\infty} e^{-\sigma(\tau-t)}\left[Y_{a}+Y_{n}-C\left(\dot{L}_{n}, L_{n}\right)\right] d \tau
$$

where $\sigma$ is the discount rate. Since the representative individual is not a social planner she does not take into account the presence of the agglomeration externality in the non-agricultural sector when choosing the optimal migration path; neither does she internalize the externality generated by the crowding diseconomy in $C(\cdot)$.

We characterize the solution to the sequence problem defined by (18) using a dynamic programming argument. From the envelope theorem, and the fact that the representative individual does not internalize the effects of the agglomeration economies or the crowding diseconomies, we have:

$$
\frac{d V\left(L_{n}\right)}{d L_{n}}=q=\int_{\tau=t}^{\infty} e^{-\sigma(\tau-t)}\left[w_{n}-w_{a}\right] d \tau
$$

where $q$ is equal to the market value of having an additional unit of labor in nonagriculture instead of agriculture; that is, the expected net present value of future wage premia that an individual realizes from migrating.

To derive a continuous time Bellman Equation we begin with the discrete time optimality condition:

$$
V\left(L_{n}\right)=\max _{\left\{\dot{L}_{n}\right\}}\left[\left(Y_{a}+Y_{n}-C\left(\dot{L}_{n}, L_{n}\right)\right) \Delta t+(1+\sigma \Delta t)^{-1} V\left(L_{n}^{\prime}\right)\right]
$$

where $L_{n}^{\prime}=L_{n}+\Delta L_{n}$. Rearranging yields:

$$
\sigma V\left(L_{n}\right) \Delta t=\max _{\left\{\dot{L}_{n}\right\}}\left[(1+\sigma \Delta t)\left(Y_{a}+Y_{n}-C\left(\dot{L}_{n}, L_{n}\right)\right) \Delta t+V\left(L_{n}^{\prime}\right)-V\left(L_{n}\right)\right]
$$

Letting $\Delta t \rightarrow 0$ and setting all terms of $d t^{2}$ or higher equal to zero yields the continuous time Bellman Equation:

$$
\sigma V\left(L_{n}\right) d t=\max _{\left\{\dot{L}_{n}\right\}}\left[\left(Y_{a}+Y_{n}-C\left(\dot{L}_{n}, L_{n}\right)\right) d t+q \dot{L}_{n} d t\right]
$$


The first order condition for optimal migration is:

$$
C_{1}\left(\dot{L}_{n}, L_{n}\right)=q
$$

Migrants therefore equate marginal moving costs with the net present value of expected wage premia from switching sectors. Inverting (21) yields the optimal migration rate:

$$
\dot{L}_{n}=C_{1}^{-1}\left(q, L_{n}\right)
$$

Migration is increasing in the discounted expected stream of future wage premia, $q$. Optimal behavior, or rationality, also imposes constraints on the path of $q$ over time. Differentiating (19) with respect to time yields:

$$
\sigma q=w_{n}-w_{a}+\dot{q}
$$

The cost of staying in the non-agricultural sector, $\sigma q$, equals the current wage premium, $w_{n}-w_{a}$, plus "capital gains" or increases in the expected value of future wage premia, $\dot{q}$. Equation (23) makes explicit the importance of expectations regarding future wage paths on migration behavior. Positive migration from agriculture to non-agriculture may occur, even if such a movement is associated with an instantaneous wage loss, when the long run gains from switching sectors are expected to be high.

To evaluate the local stability properties of the dynamic system defined by (22) and (23) we linearize the system around a steady state. For simplicity consider the case where $C(\cdot)$ takes a quadratic form such that $C\left(\dot{L}_{n}, L_{n}\right)=1 / 2 \eta_{1}\left(\dot{L}_{n}\right)^{2}+$ $\left(1 / 2 \eta_{2}\right)\left(L_{n}+f\right) \dot{L}_{n}$; where $f$ represents fixed moving costs. We can then rewrite (22) as:

$$
\dot{L}_{n}=\eta_{1} q-\frac{\eta_{1}}{\eta_{2}}\left(L_{n}+f\right)
$$

The Jacobian matrix of coefficients for this system is thus:

$$
A=\left[\begin{array}{cc}
\sigma & -\frac{\delta\left(w_{n}-w_{a}\right)}{\delta L_{n}} \\
\eta_{1} & -\frac{\eta_{1}}{\eta_{2}}
\end{array}\right]
$$

The roots of the linearized system $\left(\varsigma_{1}, \varsigma_{2}\right)$ are defined by $\operatorname{tr}(A)=\varsigma_{1}+\varsigma_{2}$ and $\operatorname{det}(A)=\varsigma_{1} \varsigma_{2}$. A sufficient condition for local stability of all equilibria is therefore $\sigma<\frac{\eta_{1}}{\eta_{2}}{ }^{20}$ The interaction of expectations, increasing returns, and a small

\footnotetext{
${ }^{20}$ Saddle-stability holds when $\operatorname{det}(A)<0$, which holds at the high output equilibrium, but not the low output equilibrium.
} 


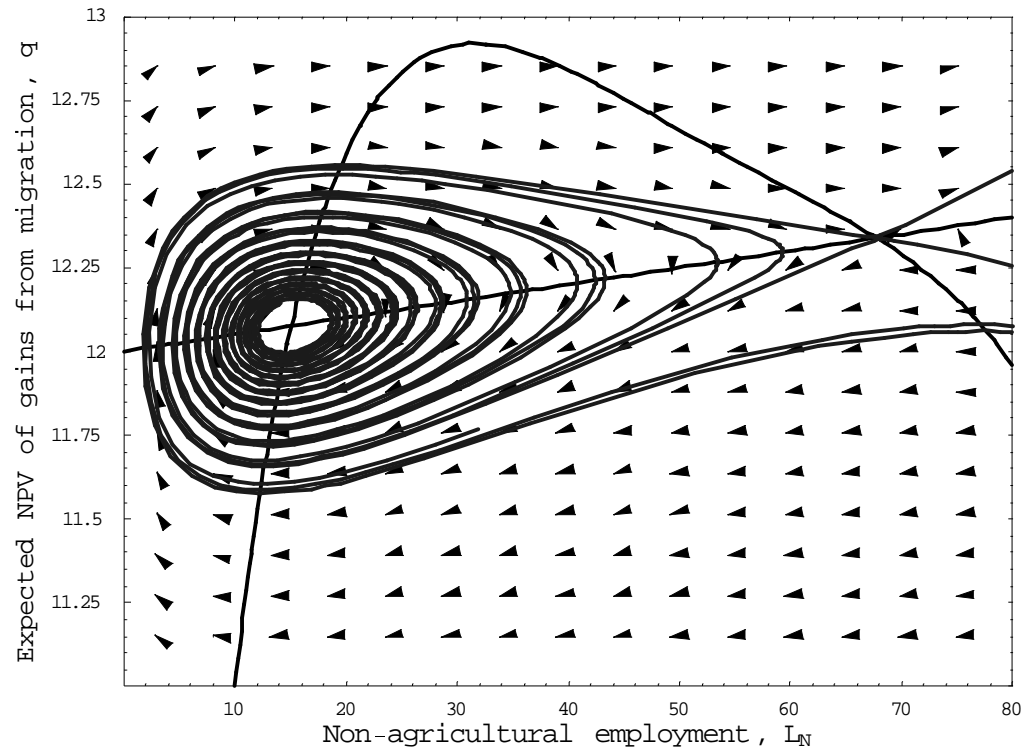

Figure 5: EXPECTATIONS AND EQUILIBRIUM STABILITY

NOTES: The figure depicts the migration dynamics for the system defined by the system of differential equations (24) and (23). The figure illustrates that under our fully specified migration process both of the interior equilibria are locally stable and thus observable under occasional perturbation. However, our migration model also gives rise to local indeterminacy, generating multiple perfect foresight paths for any given initial labor allocation.

crowding diseconomy can result in local stability of all interior equilibria if individuals are sufficiently patient (small $\sigma$ ) or the crowding diseconomy is relatively strong (small $\eta_{2}$ ).

A set of representative dynamics for the system defined by (23) and (24) are depicted in Figure 5. The dynamics of the system can be quite complex, but all our empirical exercise requires is local stability of the two interior equilibria. This is a sufficient condition for both equilibria to be observable under occasional perturbation. For a more detailed discussion of the interaction between expectations and stability in the context of increasing returns, see Howitt and McAfee (1988), Krugman (1991), and Matsuyama (1991). Graham (2000) provides an extensive discussion in the context of the present model.

We now briefly discuss the implications of this analysis for the equilibrium wage gap. The dynamics for $L_{n}$ and $q$ described by (23) and (24) imply that in 
equilibrium, the intersectoral wage gap will equal

$$
w_{n}-w_{a}=\frac{\sigma}{\eta_{2}}\left(L_{n}+f\right)
$$

In contrast, the model we calibrate is based on a simpler equilibrium condition, namely that the wage ratio is the same for both equilibria. Hence we must think of our calibrated model as only an approximation to the one analyzed here, with its more complete specification of the migration process.

In the more complete model, equation (26) shows that the wage gap between sectors is greater in the high output than in the low output equilibrium. This is potentially compatible with our calibration assumption that the wage ratio is fixed across equilibria. Since wages are greater in the high output than in the low output equilibrium, a fixed wage ratio corresponds to a wage gap that is greater in the high output equilibrium.

\section{Appendix 2: Calibration}

This appendix shows how to derive an expression that an alternative equilibrium factor allocation must satisfy, and thus forms the basis for our calibration exercise. It also sketches a proof that there will be at most two equilibria, under a parameter restriction described below, and provides a simple method for distinguishing whether an observed economy is in a low or high output equilibrium.

In what follows, we denote the fraction of total capital allocated to agriculture in the observed equilibrium by $x . Y_{a}^{\prime}$ and $Y_{n}^{\prime}$ are the agricultural and nonagricultural output levels associated with the alternative equilibrium, if one exists. The derivation starts from the payment of private marginal products to capital and labor:

$$
\begin{gathered}
w_{a}=(1-\alpha-\beta) \frac{Y_{a}}{a L} \\
r_{a}=\alpha \frac{Y_{a}}{x K} \\
w_{n}=(1-\gamma) \frac{Y_{n}}{(1-a) L} \\
r_{n}=\gamma \frac{Y_{n}}{(1-x) K}
\end{gathered}
$$


We substitute the expressions for wages into the labor market equilibrium condition (7), which implies:

$$
(1-\alpha-\beta) \frac{Y_{a}}{a L}=\left(\frac{1}{1+\delta}\right)(1-\gamma) \frac{Y_{n}}{(1-a) L}
$$

This indicates that we can express the ratio of value added in the two sectors as a function of the technology parameters, the agricultural employment share, and the intersectoral wage differential:

$$
\frac{Y_{a}}{Y_{n}}=\frac{s}{1-s}=\left(\frac{1-\gamma}{1-\alpha-\beta}\right)\left(\frac{a}{1-a}\right)\left(\frac{1}{1+\delta}\right)
$$

This equation demonstrates that the intersectoral wage differential $\left(w_{n} / w_{a}=1+\delta\right)$ is a function of the technology parameters and the observable variables $a$ and $s$.

An equation of this form must also hold in any alternative equilibrium with incomplete specialization. For this alternative equilibrium, we use $v$ to denote agriculture's share of value added, and $b$ the share of employment allocated to agriculture. So the corresponding equation will be:

$$
\frac{Y_{a}^{\prime}}{Y_{n}^{\prime}}=\frac{v}{1-v}=\left(\frac{1-\gamma}{1-\alpha-\beta}\right)\left(\frac{b}{1-b}\right)\left(\frac{1}{1+\delta}\right)
$$

Equations (32) and (33) imply that:

$$
\frac{v}{1-v}=\left(\frac{b}{1-b}\right)\left(\frac{s}{1-s}\right)\left(\frac{1-a}{a}\right)
$$

Next we derive an equation for the proportion of capital allocated to agriculture, $x$, in the observed equilibrium. We denote the rental rate by $r\left(=r_{a}=r_{n}\right)$. This implies that:

$$
\begin{aligned}
x & =\frac{K_{a}}{K}=\frac{r K_{a}}{Y_{a}} \frac{Y}{r K} \frac{Y_{a}}{Y} \\
& =\frac{s \alpha}{s \alpha+(1-s) \gamma}
\end{aligned}
$$

where the last line uses marginal productivity factor pricing (so that $r K_{a} / Y_{a}=$ $\alpha$, see equation 28) and the identity that holds for the aggregate capital share $(r K / Y=s \alpha+(1-s) \gamma)$. 
Once again, if there is an alternative equilibrium with incomplete specialization, the fraction of capital allocated to agriculture in that equilibrium (which we denote $z$ ) must satisfy a corresponding equation:

$$
z=\frac{K_{a}^{\prime}}{K}=\frac{v \alpha}{v \alpha+(1-v) \gamma}
$$

and together with equation (34) this allows us to write $z$ in terms of $b, s$ and $a$ and technology parameters:

$$
z=\frac{\frac{b}{1-b} \frac{s}{1-s} \frac{1-a}{a}\left(\frac{\alpha}{\gamma}\right)}{\frac{b}{1-b} \frac{s}{1-s} \frac{1-a}{a}\left(\frac{\alpha}{\gamma}\right)+1}
$$

The system of equations is completed by making use of the production functions, to write down the ratio of agricultural to non-agricultural output for both possible equilibria. Using our sectoral production functions (2) and (5) we get:

$$
\begin{aligned}
& \frac{s}{1-s}=\frac{Y_{a}}{Y_{n}}=\frac{[x K]^{\alpha} R^{\beta}\left[A_{a} h a L\right]^{1-\alpha-\beta}}{[(1-x) K]^{\gamma(1+\lambda)}\left[A_{n} h(1-a) L\right]^{(1-\gamma)(1+\lambda)}} \\
& \frac{v}{1-v}=\frac{Y_{a}^{\prime}}{Y_{n}^{\prime}}=\frac{[z K]^{\alpha} R^{\beta}\left[A_{a} h b L\right]^{1-\alpha-\beta}}{[(1-z) K]^{\gamma(1+\lambda)}\left[A_{n} h(1-b) L\right]^{(1-\gamma)(1+\lambda)}}
\end{aligned}
$$

Dividing (39) by (38), simplifying, and using expression (34) yields the following equation:

$$
1=\left(\frac{z}{x}\right)^{\alpha}\left(\frac{1-x}{1-z}\right)^{\gamma(1+\lambda)}\left(\frac{a}{b}\right)^{\alpha+\beta}\left(\frac{1-a}{1-b}\right)^{(1-\gamma)(1+\lambda)-1}
$$

The next step is to use the two equations for the intersectoral capital allocations ( $x$ and $z$ ) to eliminate these variables from (40). When this is done, we obtain our key equation:

$$
1=\left(\frac{a}{b}\right)^{\beta}\left(\frac{1-a}{1-b}\right)^{\lambda}\left[\frac{1-a\left(1-\frac{\alpha}{\gamma} \frac{s}{1-s} \frac{1-a}{a}\right)}{1-b\left(1-\frac{\alpha}{\gamma} \frac{s}{1-s} \frac{1-a}{a}\right)}\right]^{\alpha-\gamma(1+\lambda)}
$$

which can be expressed as equation (9) in the text. 
This has reduced the system to one equation and one unknown, $b$. The solutions represent all the allocations of labor that satisfy the equilibrium conditions, one of which will be the observed equilibrium labor allocation $a$. The underlying intersectoral capital allocations are easily recovered using equations (35) and (37).

We now investigate the number of equilibria, and also provide a simple way to distinguish whether an observed economy is in a low output or high output equilibrium. We start by rewriting (41) as:

$$
\begin{aligned}
g(a) & =g(b) \\
\text { where } g(q) & =q^{\beta}(1-q)^{\lambda}\left[1-q\left(1-\frac{\alpha}{\gamma} \frac{s}{1-s} \frac{1-a}{a}\right)\right]^{\alpha-\gamma(1+\lambda)}
\end{aligned}
$$

This equation must be satisfied by all equilibrium allocations of labor with incomplete specialization. We now show that under the parameter restriction

$$
\gamma(1+\lambda)-\lambda<\alpha<\gamma \frac{a}{1-a} \frac{1-s}{s}
$$

there will be at most two equilibria with incomplete specialization.

The underlying idea of the proof can be gained by considering a plot of $\log g(a)$ and $\log g(b)$ against all the potential values of $b$, that is for $b \in(0,1)$. An example is shown in Figure 6. Clearly $\log g(a)$ is a horizontal line since the quantity $a$ is fixed by the data. The intersections of $\log g(b)$ with this horizontal line correspond to the possible equilibrium employment allocations, since at these points $g(a)=$ $g(b)$. Note also that $g(0)=0$ and $g(1)=0$.

Hence a sufficient condition for there to exist at most two solutions between zero and one is that the curve $\log g(b)$ should be strictly concave. This implies that $\log g(b)$ crosses the straight $\operatorname{line} \log g(a)$ twice at most, for values of $b$ where $0<b<1$.

To show strict concavity of $\log g(b)$, we will use (42) to write:

$$
g(b)=b^{\beta}(1-b)^{\lambda}[1-b k]^{\theta}
$$

where $k=1-\frac{\alpha}{\gamma} \frac{s}{1-s} \frac{1-a}{a}$ and $\theta=\alpha-\gamma(1+\lambda)$. Note that our parameter restriction (43) can be rewritten as $\theta+\lambda>0$ and $0<k$. Also, since $a, s, \alpha$ and $\gamma$ all lie between zero and one, then $k<1$.

If $\theta>0$ then it is easy to show that the logarithm of (44) is strictly concave. We now show that this property also holds when $\theta>-\lambda$. We can rewrite (44) as:

$$
g(b)=b^{\beta}\left(\frac{1-b}{1-b k}\right)^{\lambda}[1-b k]^{\theta+\lambda}
$$




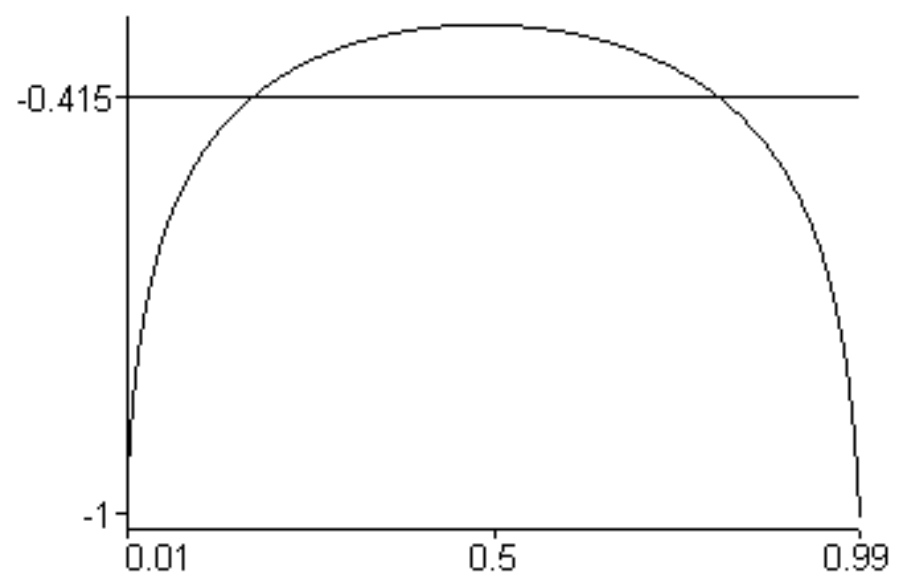

Figure 6: ON THE NUMBER OF EQUILIBRIA NOTES: An example sketch of $\log g(a)$, the horizontal line, and $\log g(b)$, the curve. This sketch indicates that there will be at most two interior equilibria under strict concavity of $\log \mathrm{g}(\mathrm{b})$.

and so:

$$
\log g(b)=\beta \log b+\lambda \log \left(\frac{1-b}{1-b k}\right)+(\theta+\lambda) \log (1-b k)
$$

Since the sum of strictly concave functions is strictly concave, all we need to show is that each of the three terms in (45) is strictly concave. For the first term, this is obvious by inspection. It is straightforward to show that the final term is also strictly concave (noting that $\theta+\lambda>0$ by assumption).

The second term can be rewritten as follows:

$$
\lambda \log \left(\frac{1-b}{1-b k}\right)=\lambda \log \frac{1}{k}\left(1+\frac{\frac{1}{k}-1}{b-\frac{1}{k}}\right)
$$

and this implies that the second term is also strictly concave in $b$, given our assumption that $0<k<1$. This completes our sketch of the proof that, under the parameter restriction (43), there will be at most two equilibria with incomplete specialization.

We can also use this result to infer from the observed employment and output shares whether an economy is in its best available equilibrium or one with lower 
output. The key idea is that for an observed economy to be in its high output equilibrium, the leftmost intersection in the figure, the derivative of $g($.$) with respect$ to $b$ should be greater than zero when evaluated at $a$. Conversely if the derivative is less than zero when evaluated at $a$, the economy must be in a low output equilibrium. There is also a knife-edge case where $g_{b}(a)=0$; given strict concavity of $\log g($.$) this implies that there is only one equilibrium.$

We can use this idea to generate a condition that the externality parameter $(\lambda)$ must satisfy for a given economy's sectoral structure to correspond to a high output equilibrium. The derivative of $g($.$) with respect to b$, evaluated at $a$, is:

$$
g_{b}(a)=\left[\frac{\beta}{a}-\frac{\lambda}{1-a}-\frac{\theta k}{1-a k}\right] g
$$

Since $a k<1$ and therefore $g>0$, the sign of $g_{b}(a)$ can be evaluated from the bracketed term alone. Substituting in for $\theta$ and $k$, and rearranging, we can rewrite the condition that $g_{b}(a)>0$ as the condition that $\lambda<\lambda^{*}$, where the critical value $\lambda^{*}$ is given by:

$$
\lambda^{*}=\frac{a(\gamma-\alpha)+\beta(1-a)-(\gamma-\alpha-\beta)(\alpha / \gamma)(1-a)\left(\frac{s}{1-s}\right)}{a(1-\gamma)+\alpha\left(\frac{s}{1-s}\right)\left[1+a\left(\frac{1-\gamma}{\gamma}\right)\right]}
$$

This is the critical value discussed at several points in the main text.

We now turn to the welfare effects associated with equilibrium switching, by showing how to calculate the ratio of output in the alternative equilibrium to that in the current one. Here we use $b$ to denote the alternative equilibrium labor allocation to that observed $(a)$. The quantity of interest is:

$$
\Lambda_{F}=\frac{Y_{a}^{\prime}+p Y_{n}^{\prime}}{Y_{a}+p Y_{n}}
$$

which can be rewritten as:

$$
\Lambda_{F}=\frac{Y_{n}^{\prime}\left(1+\frac{Y_{a}^{\prime}}{p Y_{n}^{\prime}}\right)}{Y_{n}\left(1+\frac{Y_{a}}{p Y_{n}}\right)}
$$

Now we make use of the non-agricultural production function, together with equation (34). This yields:

$$
\Lambda_{F}=\left(\frac{1-b}{1-a}\right)^{(1-\gamma)(1+\lambda)}\left(\frac{1-z}{1-x}\right)^{\gamma(1+\lambda)}\left[\frac{1+\left(\frac{b}{1-b}\right)\left(\frac{1-a}{a}\right)\left(\frac{s}{1-s}\right)}{1+\frac{s}{1-s}}\right]
$$


Substituting in the expressions for $z$ and $x$ and simplifying yields the output ratio associated with an equilibrium switch, equation (13) in the text.

\section{Appendix 3: Data sources}

Our dataset builds upon that assembled by Hall and Jones (1999). We use their GDP per worker data, as well as their aggregate human and physical capital stock estimates. We add an estimate of agricultural land area using data from the FAO Yearbook: Production. Our measure corresponds to arable and pastoral land combined.

Our data on the sectoral structure of output and employment come primarily from the World Development Indicators 2000 CD-ROM. This source is supplemented where necessary with figures drawn from the United Nations' Yearbook of National Accounts Statistics (1980) and its successor National Accounts Statistics: Main Aggregates and Detailed Tables (1991, 1994, 1995), The United Nations' Statistical Yearbook CD-ROM, various World Development Reports, and Mitchell's (1998a, 1998b, 1998c) handbooks of historical statistics. In a few cases, the figures were obtained directly from national sources, but over 90 percent of the observations are drawn directly from World Bank or UN sources.

Since the Hall and Jones (1999) output data are measured net of mining output, we adjust our sectoral value added data accordingly, using their estimate for the fraction of total GDP due to mining. Data limitations preclude a corresponding adjustment to the employment data, so we assume that total employment in the mining sector is zero. The distortions introduced by this assumption are modest given the enclave nature of mining and its high capital intensity. Even in a highly mineral dependent economy such as Botswana, where roughly one half of GDP is due to mining, less than five percent of the labor force works in the mining sector.

Tables A.1 and A.2 below report the data used for calibration as well as a set of country-by-country results for the case of $\lambda=0.30$. 


\begin{tabular}{|c|c|c|c|c|c|c|c|c|}
\hline $\begin{array}{c}\text { WB } \\
\text { Country } \\
\text { Code }\end{array}$ & Country & $\begin{array}{l}\text { Agricultural } \\
\text { Employment } \\
\text { Share }\end{array}$ & $\begin{array}{c}\text { Adjusted } \\
\text { Agricultural } \\
\text { Value Added } \\
\text { Share } \\
\end{array}$ & $\begin{array}{c}\text { Log of } \\
\text { GDP per } \\
\text { worker } \\
\text { (net mining) }\end{array}$ & $\begin{array}{c}\text { Log of } \\
\text { capital } \\
\text { per } \\
\text { worker }\end{array}$ & $\begin{array}{c}\text { Log of } \\
\text { human } \\
\text { capital per } \\
\text { worker }\end{array}$ & $\begin{array}{c}\text { Log of } \\
\text { the } \\
\text { total labor } \\
\text { force }\end{array}$ & $\begin{array}{l}\text { Log of } \\
\text { agricultural } \\
\text { land }\end{array}$ \\
\hline$\overline{\mathrm{DZA}}$ & Algeria & 27.9 & 14.4 & 9.36 & 10.31 & 0.32 & 15.50 & $\overline{10.54}$ \\
\hline AGO & Angola & 74.9 & 21.7 & 7.06 & 6.55 & 0.42 & 15.27 & 10.39 \\
\hline ARG & Argentina & 12.3 & 9.2 & 9.60 & 10.41 & 0.81 & 16.23 & 12.09 \\
\hline AUS & Australia & 5.7 & 4.5 & 10.30 & 11.39 & 1.09 & 15.87 & 13.06 \\
\hline AUT & Austria & 8.2 & 3.1 & 10.13 & 11.18 & 0.80 & 15.09 & 8.16 \\
\hline BGD & Bangladesh & 67.0 & 29.8 & 8.41 & 7.40 & 0.26 & 17.21 & 9.20 \\
\hline BRB & Barbados & 7.2 & 6.5 & 9.57 & 9.84 & 0.89 & 11.79 & 3.61 \\
\hline BEL & Belgium & 2.7 & 1.9 & 10.30 & 11.24 & 1.02 & 15.23 & 7.32 \\
\hline BEN & Benin & 64.3 & 34.7 & 7.64 & 7.54 & 0.09 & 14.57 & 7.74 \\
\hline $\mathrm{BOL}$ & Bolivia & 48.1 & 23.0 & 8.51 & 9.11 & 0.56 & 14.57 & 10.31 \\
\hline BWA & Botswana & 50.0 & 11.4 & 8.11 & 9.20 & 0.50 & 12.91 & 10.72 \\
\hline BRA & Brazil & 25.8 & 10.3 & 9.33 & 9.96 & 0.47 & 17.78 & 12.42 \\
\hline BFA & Burkina Faso & 92.4 & 32.8 & 6.95 & 6.77 & 0.51 & 15.26 & 9.52 \\
\hline BDI & Burundi & 91.9 & 54.8 & 6.96 & 6.46 & 0.27 & 14.82 & 7.72 \\
\hline CMR & Cameroon & 70.4 & 27.0 & 7.90 & 8.04 & 0.30 & 15.40 & 9.64 \\
\hline CAN & Canada & 3.9 & 3.0 & 10.41 & 11.32 & 1.10 & 16.38 & 11.27 \\
\hline CPV & Cape Verde & 31.8 & 17.7 & 7.89 & 8.78 & 0.45 & 11.80 & 4.17 \\
\hline CAF & Central African Republic & 81.2 & 49.7 & 7.07 & 6.89 & 0.17 & 14.14 & 8.52 \\
\hline TCD & Chad & 84.3 & 36.8 & 7.04 & 5.88 & 0.35 & 14.45 & 10.78 \\
\hline $\mathrm{CHL}$ & Chile & 19.2 & 10.0 & 9.14 & 10.02 & 0.78 & 15.34 & 9.78 \\
\hline $\mathrm{CHN}$ & China & 72.6 & 26.9 & 7.66 & 8.33 & 0.74 & 20.30 & 12.94 \\
\hline $\mathrm{COL}$ & Colombia & 29.2 & 20.6 & 9.14 & 9.64 & 0.59 & 16.13 & 10.73 \\
\hline $\mathrm{COM}$ & Comoros & 78.0 & 42.5 & 7.13 & 7.77 & 0.41 & 12.20 & 4.74 \\
\hline ZAR & Congo, Dem. Rep. & 68.6 & 30.2 & 7.05 & 6.57 & 0.30 & 16.41 & 10.04 \\
\hline $\mathrm{COG}$ & Congo, Rep. & 50.6 & 16.7 & 8.37 & 8.50 & 0.42 & 13.78 & 9.23 \\
\hline CRI & Costa Rica & 27.7 & 16.6 & 9.12 & 9.72 & 0.67 & 13.81 & 7.95 \\
\hline CIV & Cote d'Ivoire & 60.9 & 33.0 & 8.14 & 8.44 & 0.39 & 15.30 & 8.80 \\
\hline CYP & Cyprus & 15.6 & 7.2 & 9.67 & 10.52 & 0.85 & 12.67 & 5.09 \\
\hline CSK & Czechoslovakia & 11.9 & 7.5 & 8.92 & 10.09 & 0.93 & 15.92 & 8.82 \\
\hline DNK & Denmark & 5.8 & 4.4 & 10.10 & 11.16 & 1.10 & 14.86 & 7.93 \\
\hline DOM & Dominican Republic & 26.3 & 16.1 & 8.90 & 9.41 & 0.55 & 14.56 & 8.18 \\
\hline ECU & Ecuador & 34.5 & 15.9 & 9.03 & 9.96 & 0.70 & 14.93 & 8.95 \\
\hline EGY & Egypt, Arab Rep. & 43.6 & 19.6 & 8.80 & 8.13 & 0.65 & 16.44 & 7.86 \\
\hline SLV & El Salvador & 37.7 & 21.0 & 8.62 & 8.63 & 0.48 & 14.31 & 7.20 \\
\hline FJI & Fiji & 46.0 & 20.3 & 9.18 & 9.92 & 0.81 & 12.40 & 5.70 \\
\hline FIN & Finland & 9.0 & 6.6 & 10.17 & 11.40 & 1.04 & 14.75 & 7.85 \\
\hline FRA & France & 6.0 & 3.4 & 10.27 & 11.35 & 0.79 & 17.05 & 10.35 \\
\hline GAB & Gabon & 54.4 & 12.8 & 8.62 & 10.06 & 0.30 & 13.12 & 8.55 \\
\hline GMB & Gambia, The & 82.4 & 31.1 & 7.45 & 7.10 & 0.11 & 12.86 & 5.58 \\
\hline DEU & Germany, West & 4.5 & 1.7 & 10.27 & 11.40 & 0.98 & 17.16 & 9.39 \\
\hline GHA & Ghana & 59.7 & 50.4 & 7.53 & 7.10 & 0.43 & 15.61 & 8.74 \\
\hline GRC & Greece & 24.5 & 13.3 & 9.72 & 10.66 & 0.81 & 15.16 & 9.13 \\
\hline GTM & Guatemala & 52.7 & 25.9 & 8.91 & 8.96 & 0.35 & 14.72 & 8.08 \\
\hline GIN & Guinea & 88.0 & 25.4 & 7.33 & 6.91 & 0.32 & 14.75 & 8.22 \\
\hline GNB & Guinea-Bissau & 85.8 & 58.1 & 7.24 & 7.83 & 0.08 & 13.00 & 7.25 \\
\hline GUY & Guyana & 22.8 & 28.5 & 8.23 & 9.57 & 0.65 & 12.57 & 7.45 \\
\hline $\mathrm{HTI}$ & Haiti & 68.4 & 36.4 & 7.61 & 7.40 & 0.22 & 14.78 & 7.44 \\
\hline HND & Honduras & 44.5 & 21.5 & 8.43 & 8.73 & 0.48 & 14.20 & 8.37 \\
\hline HKG & Hong Kong, China & 1.0 & 0.3 & 9.98 & 10.28 & 0.89 & 15.11 & 2.08 \\
\hline HUN & Hungary & 15.9 & 17.3 & 9.29 & 10.43 & 1.13 & 15.47 & 8.78 \\
\hline ISL & Iceland & 10.9 & 12.1 & 10.16 & 11.11 & 0.93 & 11.80 & 7.73 \\
\hline IND & India & 65.2 & 32.7 & 8.02 & 8.24 & 0.41 & 19.57 & 12.11 \\
\hline IDN & Indonesia & 55.7 & 25.6 & 8.27 & 9.00 & 0.50 & 18.02 & 10.40 \\
\hline IRN & Iran, Islamic Rep. & 40.1 & 25.2 & 9.25 & 10.12 & 0.44 & 16.54 & 10.98 \\
\hline IRL & Ireland & 15.1 & 9.8 & 9.93 & 10.93 & 0.94 & 14.12 & 8.64 \\
\hline
\end{tabular}




\begin{tabular}{|c|c|c|c|c|c|c|c|c|}
\hline $\begin{array}{c}\text { World Bank } \\
\text { Country } \\
\text { Code }\end{array}$ & Country & $\begin{array}{l}\text { Agricultural } \\
\text { Employment } \\
\text { Share }\end{array}$ & $\begin{array}{c}\text { Adjusted } \\
\text { Agricultural } \\
\text { Value Added } \\
\text { Share } \\
\end{array}$ & $\begin{array}{c}\text { Log of } \\
\text { GDP per } \\
\text { worker } \\
\text { (net mining) } \\
\end{array}$ & $\begin{array}{l}\text { Log of } \\
\text { capital } \\
\text { per } \\
\text { worker }\end{array}$ & $\begin{array}{c}\text { Log of } \\
\text { human } \\
\text { capital per } \\
\text { worker }\end{array}$ & $\begin{array}{c}\text { Log of } \\
\text { the } \\
\text { total labor } \\
\text { force }\end{array}$ & $\begin{array}{c}\text { Log of } \\
\text { agricultural } \\
\text { land }\end{array}$ \\
\hline ISR & Israel & 4.5 & 3.4 & 10.06 & 10.85 & 1.04 & 14.35 & 6.36 \\
\hline ITA & Italy & 9.3 & 3.6 & 10.29 & 11.32 & 0.77 & 16.96 & 9.74 \\
\hline JAM & Jamaica & 26.0 & 7.9 & 8.43 & 9.46 & 0.55 & 13.93 & 6.14 \\
\hline JPN & Japan & 7.9 & 2.7 & 9.94 & 11.07 & 0.97 & 18.16 & 8.58 \\
\hline JOR & Jordan & 15.8 & 7.2 & 9.60 & 10.01 & 0.57 & 13.43 & 7.06 \\
\hline KEN & Kenya & 80.1 & 31.5 & 7.60 & 7.92 & 0.41 & 16.13 & 8.73 \\
\hline KOR & Korea, Rep. & 21.2 & 10.1 & 9.51 & 10.11 & 0.92 & 16.67 & 7.71 \\
\hline LSO & Lesotho & 40.2 & 24.9 & 7.71 & 7.84 & 0.47 & 13.58 & 7.75 \\
\hline LUX & Luxembourg & 3.9 & 1.9 & 10.46 & 11.58 & 0.98 & 11.98 & 4.76 \\
\hline MDG & Madagascar & 78.9 & 36.3 & 7.27 & 5.76 & 0.53 & 15.39 & 10.52 \\
\hline MWI & Malawi & 86.8 & 54.4 & 6.95 & 7.08 & 0.35 & 15.05 & 8.35 \\
\hline MYS & Malaysia & 29.8 & 21.5 & 9.16 & 10.07 & 0.67 & 15.74 & 8.50 \\
\hline MLI & Mali & 86.5 & 45.5 & 7.11 & 6.72 & 0.11 & 15.01 & 10.38 \\
\hline MLT & Malta & 3.3 & 4.0 & 9.71 & 10.40 & 0.83 & 11.74 & 2.56 \\
\hline MRT & Mauritania & 58.7 & 35.1 & 7.49 & 8.31 & 0.34 & 13.55 & 10.59 \\
\hline MUS & Mauritius & 18.6 & 13.1 & 9.13 & 9.06 & 0.60 & 13.30 & 4.73 \\
\hline MEX & Mexico & 29.6 & 7.5 & 9.64 & 10.26 & 0.58 & 17.10 & 11.50 \\
\hline MAR & Morocco & 46.9 & 17.7 & 8.80 & 8.74 & 0.64 & 15.83 & 10.30 \\
\hline MOZ & Mozambique & 83.0 & 46.8 & 7.23 & 6.03 & 0.14 & 15.83 & 10.76 \\
\hline MMR & Myanmar & 73.8 & 57.8 & 6.93 & 7.02 & 0.27 & 16.70 & 9.25 \\
\hline NAM & Namibia & 50.6 & 16.5 & 8.84 & 10.19 & 0.46 & 12.92 & 10.89 \\
\hline NLD & Netherlands & 4.8 & 4.0 & 10.26 & 11.28 & 0.98 & 15.62 & 7.61 \\
\hline NZL & New Zealand & 10.6 & 7.4 & 10.14 & 11.27 & 1.21 & 14.21 & 9.57 \\
\hline NIC & Nicaragua & 29.9 & 30.0 & 8.40 & 9.08 & 0.51 & 13.89 & 8.79 \\
\hline NER & Niger & 90.2 & 38.3 & 6.92 & 7.05 & 0.07 & 15.08 & 9.46 \\
\hline NGA & Nigeria & 45.2 & 51.3 & 7.45 & 8.22 & 0.20 & 17.49 & 10.87 \\
\hline NOR & Norway & 6.6 & 3.6 & 10.20 & 11.46 & 1.10 & 14.56 & 6.87 \\
\hline OMN & Oman & 45.6 & 7.2 & 9.62 & 10.77 & 0.63 & 12.91 & 6.95 \\
\hline PAK & Pakistan & 53.4 & 26.2 & 8.42 & 8.24 & 0.26 & 17.27 & 10.16 \\
\hline PAN & Panama & 26.7 & 10.2 & 8.97 & 9.89 & 0.77 & 13.63 & 7.55 \\
\hline PNG & Papua New Guinea & 79.9 & 36.1 & 7.92 & 8.72 & 0.22 & 14.38 & 6.16 \\
\hline PRY & Paraguay & 40.2 & 29.8 & 8.70 & 9.18 & 0.61 & 14.11 & 9.75 \\
\hline PER & Peru & 36.6 & 10.5 & 9.03 & 9.80 & 0.72 & 15.70 & 10.34 \\
\hline PHL & Philippines & 47.1 & 23.4 & 8.41 & 8.99 & 0.79 & 16.89 & 9.13 \\
\hline POL & Poland & 27.9 & 13.7 & 9.04 & 10.43 & 0.97 & 16.78 & 9.84 \\
\hline PRT & Portugal & 19.3 & 6.0 & 9.47 & 10.29 & 0.51 & 15.34 & 8.10 \\
\hline PRI & Puerto Rico & 4.6 & 1.5 & 10.13 & 10.66 & 0.60 & 13.96 & 6.14 \\
\hline REU & Reunion & 9.4 & 5.2 & 8.99 & 9.57 & 0.52 & 12.36 & 4.16 \\
\hline ROM & Romania & 25.9 & 15.9 & 8.30 & 9.27 & 0.70 & 16.25 & 9.62 \\
\hline RWA & Rwanda & 91.9 & 42.9 & 7.32 & 6.59 & 0.11 & 14.99 & 7.32 \\
\hline SAU & Saudi Arabia & 23.1 & 9.5 & 9.84 & 10.53 & 0.62 & 15.23 & 11.36 \\
\hline SEN & Senegal & 77.6 & 22.6 & 7.84 & 7.26 & 0.32 & 14.98 & 9.30 \\
\hline SYC & Seychelles & 10.3 & 4.7 & 8.94 & 9.41 & 0.30 & 10.29 & 1.79 \\
\hline SLE & Sierra Leone & 67.9 & 57.1 & 7.73 & 6.16 & 0.23 & 14.18 & 8.30 \\
\hline SGP & Singapore & 0.5 & 0.4 & 9.97 & 10.94 & 0.59 & 14.04 & 0.69 \\
\hline SOM & Somalia & 75.9 & 69.5 & 7.45 & 7.59 & 0.31 & 15.03 & 10.31 \\
\hline ZAF & South Africa & 14.2 & 6.6 & 9.09 & 9.91 & 0.63 & 16.32 & 11.46 \\
\hline SUN & Soviet Union & 18.4 & 23.2 & 9.60 & 10.92 & 0.87 & 18.79 & 13.31 \\
\hline ESP & Spain & 13.0 & 5.3 & 10.09 & 11.03 & 0.70 & 16.45 & 10.33 \\
\hline LKA & Sri Lanka & 49.2 & 26.7 & 8.61 & 8.69 & 0.67 & 15.62 & 7.76 \\
\hline SDN & Sudan & 70.0 & 33.0 & 7.77 & 8.31 & 0.12 & 15.86 & 11.13 \\
\hline SUR & Suriname & 21.8 & 11.3 & 9.11 & 9.97 & 0.28 & 11.84 & 4.48 \\
\hline SWZ & Swaziland & 41.5 & 16.3 & 8.67 & 9.01 & 0.51 & 12.62 & 7.20 \\
\hline SWE & Sweden & 5.6 & 3.2 & 10.24 & 11.20 & 1.04 & 15.28 & 8.16 \\
\hline $\mathrm{CHE}$ & Switzerland & 5.6 & 2.9 & 10.34 & 11.59 & 1.01 & 15.01 & 7.61 \\
\hline
\end{tabular}




\begin{tabular}{|c|c|c|c|c|c|c|c|c|}
\hline $\begin{array}{l}\text { World Bank } \\
\text { Country } \\
\text { Code }\end{array}$ & Country & $\begin{array}{c}\text { Agricultural } \\
\text { Employment } \\
\text { Share }\end{array}$ & $\begin{array}{c}\text { Adjusted } \\
\text { Agricultural } \\
\text { Value Added } \\
\text { Share }\end{array}$ & $\begin{array}{c}\text { Log of } \\
\text { GDP per } \\
\text { worker } \\
\text { (net mining) }\end{array}$ & $\begin{array}{c}\text { Log of } \\
\text { capital } \\
\text { per } \\
\text { worker }\end{array}$ & $\begin{array}{c}\text { Log of } \\
\text { human } \\
\text { capital per } \\
\text { worker }\end{array}$ & $\begin{array}{c}\text { Log of } \\
\text { the } \\
\text { total labor } \\
\text { force }\end{array}$ & $\begin{array}{l}\text { Log of } \\
\text { agricultural } \\
\quad \text { land }\end{array}$ \\
\hline SYR & Syrian Arab Republic & 34.3 & 33.2 & 9.65 & 10.14 & 0.53 & 14.84 & 9.53 \\
\hline OAN & Taiwan & 21.8 & 5.2 & 9.67 & 10.18 & 0.84 & 15.97 & 6.88 \\
\hline TZA & Tanzania & 84.7 & 53.2 & 7.02 & 7.07 & 0.31 & 16.21 & 10.60 \\
\hline THA & Thailand & 65.5 & 16.5 & 8.62 & 8.92 & 0.65 & 17.17 & 9.95 \\
\hline TGO & Togo & 66.2 & 37.0 & 7.25 & 7.89 & 0.29 & 14.14 & 7.40 \\
\hline TTO & Trinidad and Tobago & 11.0 & 3.0 & 9.78 & 10.59 & 0.79 & 13.05 & 4.88 \\
\hline TUN & Tunisia & 30.2 & 12.8 & 8.95 & 9.29 & 0.33 & 14.73 & 8.97 \\
\hline TUR & Turkey & 54.5 & 18.1 & 8.95 & 9.70 & 0.44 & 16.96 & 10.50 \\
\hline UGA & Uganda & 85.1 & 56.8 & 7.02 & 5.90 & 0.26 & 15.78 & 9.37 \\
\hline GBR & United Kingdom & 2.3 & 1.8 & 10.16 & 10.83 & 0.98 & 17.15 & 9.83 \\
\hline USA & United States & 3.0 & 1.9 & 10.48 & 11.38 & 1.20 & 18.61 & 12.97 \\
\hline URY & Uruguay & 14.7 & 13.4 & 9.40 & 10.06 & 0.78 & 13.99 & 9.61 \\
\hline VEN & Venezuela & 12.5 & 7.5 & 9.77 & 10.66 & 0.67 & 15.66 & 9.98 \\
\hline YEM & Yemen, Rep. & 63.4 & 16.5 & 8.92 & 8.86 & 0.11 & 14.77 & 9.03 \\
\hline YUG & Yugoslavia, FR (Serbia/Monten & 31.5 & 11.5 & 9.27 & 10.60 & 0.86 & 16.19 & 9.55 \\
\hline ZMB & Zambia & 74.9 & 20.6 & 7.50 & 8.78 & 0.57 & 14.74 & 10.60 \\
\hline ZWE & Zimbabwe & 69.3 & 17.4 & 7.75 & 8.43 & 0.35 & 15.22 & 8.94 \\
\hline
\end{tabular}




\begin{tabular}{|c|c|c|c|c|c|c|c|c|c|c|}
\hline $\begin{array}{c}\text { WB } \\
\text { Country } \\
\text { Code }\end{array}$ & Country & $\begin{array}{c}\text { Dummy = } 1 \\
\text { if in low } \\
\text { output } \\
\text { equilibria }\end{array}$ & $\begin{array}{c}\text { Ratio } \\
\text { of output } \\
\text { across } \\
\text { two equilibria }\end{array}$ & $\begin{array}{l}\text { Agricultural } \\
\text { labor share } \\
\text { in low } \\
\text { equilibria }\end{array}$ & $\begin{array}{l}\text { Agricultural } \\
\text { labor share } \\
\text { in high } \\
\text { equilibria }\end{array}$ & $\begin{array}{c}\text { Agricultural } \\
\text { capital share } \\
\text { in low } \\
\text { equilibria }\end{array}$ & $\begin{array}{c}\text { Agricultural } \\
\text { capital share } \\
\text { in high } \\
\text { equilibria }\end{array}$ & $\begin{array}{c}\text { Equilibrium } \\
\text { wage wedge }\end{array}$ & $\begin{array}{l}\text { Manufacturing } \\
\text { total } \\
\text { factor } \\
\text { productivity }\end{array}$ & $\begin{array}{l}\text { Agricultural } \\
\text { total } \\
\text { factor } \\
\text { productivity }\end{array}$ \\
\hline DZA & Algeria & 0 & 1.28 & 0.56 & 0.28 & 0.16 & 0.39 & 2.75 & -0.06 & 13.50 \\
\hline AGO & Angola & 1 & 2.42 & 0.75 & 0.16 & 0.02 & 0.24 & 16.49 & 0.23 & 11.03 \\
\hline ARG & Argentina & 0 & 1.54 & 0.74 & 0.12 & 0.10 & 0.70 & 1.25 & -0.73 & 13.25 \\
\hline AUS & Australia & 0 & 1.82 & 0.85 & 0.06 & 0.05 & 0.83 & 1.10 & -0.63 & 12.76 \\
\hline AUT & Austria & 0 & 2.28 & 0.82 & 0.08 & 0.04 & 0.66 & 3.45 & -0.12 & 14.00 \\
\hline BGD & Bangladesh & 1 & 1.74 & 0.67 & 0.21 & 0.06 & 0.33 & 6.78 & 0.50 & 15.87 \\
\hline BRB & Barbados & 0 & 1.61 & 0.81 & 0.07 & 0.07 & 0.82 & 0.81 & 0.99 & 15.70 \\
\hline BEL & Belgium & 0 & 2.29 & 0.91 & 0.03 & 0.02 & 0.89 & 1.35 & -0.28 & 14.96 \\
\hline BEN & Benin & 1 & 1.57 & 0.64 & 0.22 & 0.09 & 0.38 & 4.51 & 0.50 & 13.66 \\
\hline $\mathrm{BOL}$ & Bolivia & 1 & 1.12 & 0.48 & 0.37 & 0.18 & 0.25 & 4.02 & -0.07 & 12.15 \\
\hline BWA & Botswana & 1 & 1.17 & 0.50 & 0.37 & 0.08 & 0.13 & 11.70 & 0.19 & 8.98 \\
\hline BRA & Brazil & 0 & 1.41 & 0.60 & 0.26 & 0.12 & 0.36 & 3.92 & -0.86 & 13.41 \\
\hline BFA & Burkina Faso & 1 & 6.71 & 0.92 & 0.04 & 0.00 & 0.36 & 39.37 & 1.00 & 11.30 \\
\hline BDI & Burundi & 1 & 5.07 & 0.92 & 0.03 & 0.00 & 0.58 & 14.21 & 1.27 & 13.35 \\
\hline CMR & Cameroon & 1 & 1.98 & 0.70 & 0.19 & 0.04 & 0.30 & 9.44 & 0.29 & 12.59 \\
\hline CAN & Canada & 0 & 1.99 & 0.88 & 0.04 & 0.03 & 0.87 & 1.11 & -0.66 & 14.04 \\
\hline CPV & Cape Verde & 0 & 1.18 & 0.52 & 0.32 & 0.20 & 0.36 & 2.51 & 0.25 & 12.77 \\
\hline CAF & Central African Republic & 1 & 2.53 & 0.81 & 0.10 & 0.03 & 0.53 & 6.09 & 0.73 & 12.52 \\
\hline TCD & Chad & 1 & 3.37 & 0.84 & 0.09 & 0.01 & 0.40 & 13.91 & 1.26 & 11.79 \\
\hline $\mathrm{CHL}$ & Chile & 0 & 1.51 & 0.66 & 0.19 & 0.11 & 0.52 & 2.45 & -0.66 & 12.91 \\
\hline $\mathrm{CHN}$ & China & 1 & 2.15 & 0.73 & 0.17 & 0.03 & 0.30 & 10.75 & -2.25 & 12.02 \\
\hline $\mathrm{COL}$ & Colombia & 0 & 1.18 & 0.53 & 0.29 & 0.23 & 0.45 & 1.58 & -0.48 & 14.08 \\
\hline COM & Comoros & 1 & 2.35 & 0.78 & 0.12 & 0.03 & 0.46 & 6.80 & 0.71 & 12.28 \\
\hline ZAR & Congo, Dem. Rep. & 1 & 1.83 & 0.69 & 0.20 & 0.05 & 0.33 & 7.20 & -0.36 & 12.44 \\
\hline COG & Congo, Rep. & 1 & 1.19 & 0.51 & 0.36 & 0.11 & 0.19 & 7.32 & 0.61 & 12.16 \\
\hline CRI & Costa Rica & 0 & 1.25 & 0.56 & 0.28 & 0.19 & 0.43 & 2.12 & 0.20 & 13.81 \\
\hline CIV & Cote d'Ivoire & 1 & 1.45 & 0.61 & 0.25 & 0.11 & 0.36 & 4.15 & -0.03 & 13.52 \\
\hline CYP & Cyprus & 0 & 1.70 & 0.71 & 0.16 & 0.08 & 0.55 & 2.87 & 0.55 & 14.38 \\
\hline CSK & Czechoslovakia & 0 & 1.67 & 0.75 & 0.12 & 0.08 & 0.68 & 1.71 & -1.38 & 12.95 \\
\hline DNK & Denmark & 0 & 1.85 & 0.85 & 0.06 & 0.05 & 0.82 & 1.19 & -0.39 & 14.49 \\
\hline DOM & Dominican Republic & 0 & 1.27 & 0.57 & 0.26 & 0.18 & 0.45 & 2.01 & -0.06 & 13.96 \\
\hline ECU & Ecuador & 0 & 1.16 & 0.50 & 0.35 & 0.18 & 0.29 & 3.54 & -0.34 & 13.11 \\
\hline EGY & Egypt, Arab Rep. & 1 & 1.03 & 0.44 & 0.41 & 0.20 & 0.22 & 4.14 & 0.00 & 15.81 \\
\hline SLV & El Salvador & 0 & 1.07 & 0.46 & 0.38 & 0.23 & 0.30 & 2.69 & 0.33 & 14.53 \\
\hline FJI & Fiji & 1 & 1.07 & 0.46 & 0.39 & 0.18 & 0.23 & 4.42 & 0.79 & 13.84 \\
\hline FIN & Finland & 0 & 1.69 & 0.79 & 0.09 & 0.07 & 0.75 & 1.30 & -0.33 & 14.62 \\
\hline FRA & France & 0 & 2.11 & 0.85 & 0.06 & 0.04 & 0.78 & 1.98 & -0.75 & 14.49 \\
\hline GAB & Gabon & 1 & 1.31 & 0.54 & 0.33 & 0.07 & 0.14 & 12.18 & 0.54 & 10.90 \\
\hline GMB & Gambia, The & 1 & 3.19 & 0.82 & 0.10 & 0.01 & 0.34 & 15.84 & 1.84 & 13.41 \\
\hline DEU & Germany, West & 0 & 2.74 & 0.88 & 0.04 & 0.02 & 0.77 & 3.37 & -1.01 & 14.07 \\
\hline GHA & Ghana & 1 & 1.27 & 0.60 & 0.23 & 0.19 & 0.54 & 1.37 & -0.40 & 14.13 \\
\hline GRC & Greece & 0 & 1.35 & 0.60 & 0.24 & 0.15 & 0.45 & 2.44 & -0.24 & 14.10 \\
\hline GTM & Guatemala & 1 & 1.23 & 0.53 & 0.32 & 0.15 & 0.29 & 4.17 & 0.73 & 14.81 \\
\hline GIN & Guinea & 1 & 4.75 & 0.88 & 0.06 & 0.00 & 0.28 & 34.02 & 1.35 & 12.34 \\
\hline GNB & Guinea-Bissau & 1 & 2.95 & 0.86 & 0.07 & 0.02 & 0.61 & 6.06 & 1.09 & 12.34 \\
\hline GUY & Guyana & 0 & 1.10 & 0.57 & 0.23 & 0.31 & 0.67 & 0.20 & -0.47 & 12.41 \\
\hline HTI & Haiti & 1 & 1.75 & 0.68 & 0.19 & 0.07 & 0.39 & 5.17 & 0.44 & 13.85 \\
\hline HND & Honduras & 1 & 1.05 & 0.45 & 0.40 & 0.21 & 0.24 & 3.76 & 0.21 & 13.19 \\
\hline HKG & Hong Kong, China & 0 & 4.31 & 0.96 & 0.01 & 0.00 & 0.90 & 3.90 & 0.03 & 16.19 \\
\hline HUN & Hungary & 0 & 1.24 & 0.67 & 0.16 & 0.19 & 0.72 & 0.47 & -1.17 & 14.12 \\
\hline ISL & Iceland & 0 & 1.33 & 0.75 & 0.11 & 0.14 & 0.79 & 0.43 & 0.97 & 14.34 \\
\hline IND & India & 1 & 1.62 & 0.65 & 0.22 & 0.08 & 0.36 & 5.27 & -1.48 & 13.80 \\
\hline IDN & Indonesia & 1 & 1.31 & 0.56 & 0.30 & 0.12 & 0.28 & 4.95 & -1.31 & 13.43 \\
\hline IRN & Iran, Islamic Rep. & 0 & 1.02 & 0.43 & 0.40 & 0.28 & 0.30 & 2.24 & -0.46 & 14.11 \\
\hline IRL & Ireland & 0 & 1.53 & 0.71 & 0.15 & 0.11 & 0.63 & 1.66 & 0.01 & 13.98 \\
\hline
\end{tabular}




\begin{tabular}{|c|c|c|c|c|c|c|c|c|c|c|}
\hline $\begin{array}{c}\text { WB } \\
\text { Country } \\
\text { Code }\end{array}$ & Country & $\begin{array}{l}\text { Dummy = } 1 \\
\text { if in low } \\
\text { output } \\
\text { equilibria }\end{array}$ & $\begin{array}{c}\text { Ratio } \\
\text { of output } \\
\text { across } \\
\text { two equilibria }\end{array}$ & $\begin{array}{l}\text { Agricultural } \\
\text { labor share } \\
\text { in low } \\
\text { equilibria }\end{array}$ & $\begin{array}{l}\text { Agricultural } \\
\text { labor share } \\
\text { in high } \\
\text { equilibria }\end{array}$ & $\begin{array}{c}\text { Agricultural } \\
\text { capital share } \\
\text { in low } \\
\text { equilibria }\end{array}$ & $\begin{array}{c}\text { Agricultural } \\
\text { capital share } \\
\text { in high } \\
\text { equilibria }\end{array}$ & $\begin{array}{c}\text { Equilibrium } \\
\text { wage wedge }\end{array}$ & $\begin{array}{c}\text { Manufacturing } \\
\text { total } \\
\text { factor } \\
\text { productivity }\end{array}$ & $\begin{array}{c}\text { Agricultural } \\
\text { total } \\
\text { factor } \\
\text { productivity } \\
\end{array}$ \\
\hline ISR & Israel & 0 & 1.95 & 0.87 & 0.04 & 0.04 & 0.85 & 1.15 & -0.05 & 15.17 \\
\hline ITA & Italy & 0 & 2.18 & 0.81 & 0.09 & 0.04 & 0.64 & 3.45 & -0.62 & 14.52 \\
\hline JAM & Jamaica & 0 & 1.48 & 0.61 & 0.26 & 0.09 & 0.30 & 5.70 & -0.36 & 12.37 \\
\hline JPN & Japan & 0 & 2.43 & 0.83 & 0.08 & 0.03 & 0.64 & 4.08 & -1.55 & 14.58 \\
\hline JOR & Jordan & 0 & 1.70 & 0.71 & 0.16 & 0.08 & 0.54 & 2.93 & 0.76 & 14.37 \\
\hline KEN & Kenya & 1 & 2.83 & 0.80 & 0.12 & 0.02 & 0.34 & 13.19 & -0.02 & 12.77 \\
\hline KOR & Korea, Rep. & 0 & 1.49 & 0.64 & 0.21 & 0.11 & 0.46 & 2.91 & -0.86 & 15.20 \\
\hline LSO & Lesotho & 0 & 1.02 & 0.43 & 0.40 & 0.27 & 0.29 & 2.30 & -0.04 & 12.61 \\
\hline LUX & Luxembourg & 0 & 2.51 & 0.89 & 0.04 & 0.02 & 0.82 & 2.36 & 0.94 & 14.39 \\
\hline MDG & Madagascar & 1 & 2.58 & 0.79 & 0.12 & 0.02 & 0.39 & 9.68 & 0.80 & 12.95 \\
\hline MWI & Malawi & 1 & 3.30 & 0.87 & 0.06 & 0.01 & 0.58 & 7.93 & 0.29 & 12.48 \\
\hline MYS & Malaysia & 0 & 1.16 & 0.52 & 0.30 & 0.24 & 0.45 & 1.51 & -0.63 & 14.57 \\
\hline MLI & Mali & 1 & 3.57 & 0.87 & 0.07 & 0.01 & 0.49 & 11.46 & 1.00 & 12.16 \\
\hline MLT & Malta & 0 & 1.62 & 0.89 & 0.03 & 0.05 & 0.92 & 0.32 & 0.90 & 16.09 \\
\hline MRT & Mauritania & 1 & 1.36 & 0.59 & 0.26 & 0.13 & 0.38 & 3.27 & -0.13 & 10.43 \\
\hline MUS & Mauritius & 0 & 1.39 & 0.66 & 0.19 & 0.15 & 0.59 & 1.47 & 0.74 & 15.98 \\
\hline MEX & Mexico & 0 & 1.39 & 0.57 & 0.30 & 0.08 & 0.23 & 7.44 & -0.46 & 13.26 \\
\hline MAR & Morocco & 1 & 1.09 & 0.47 & 0.39 & 0.15 & 0.20 & 5.67 & -0.03 & 13.43 \\
\hline MOZ & Mozambique & 1 & 2.87 & 0.83 & 0.09 & 0.02 & 0.50 & 8.06 & 0.95 & 13.42 \\
\hline MMR & Myanmar & 1 & 1.72 & 0.74 & 0.13 & 0.08 & 0.61 & 2.34 & -0.96 & 13.18 \\
\hline NAM & Namibia & 1 & 1.19 & 0.51 & 0.36 & 0.11 & 0.18 & 7.40 & 0.52 & 10.33 \\
\hline NLD & Netherlands & 0 & 1.82 & 0.86 & 0.05 & 0.05 & 0.86 & 0.93 & -0.43 & 15.50 \\
\hline NZL & New Zealand & 0 & 1.64 & 0.77 & 0.11 & 0.08 & 0.72 & 1.38 & -0.26 & 13.43 \\
\hline NIC & Nicaragua & 0 & 1.09 & 0.50 & 0.30 & 0.33 & 0.53 & 0.61 & -0.24 & 13.28 \\
\hline NER & Niger & 1 & 5.12 & 0.90 & 0.05 & 0.00 & 0.41 & 23.18 & 1.01 & 11.56 \\
\hline NGA & Nigeria & 1 & 1.04 & 0.45 & 0.33 & 0.42 & 0.55 & 0.28 & -1.84 & 13.24 \\
\hline NOR & Norway & 0 & 2.10 & 0.84 & 0.07 & 0.04 & 0.76 & 2.14 & -0.32 & 14.36 \\
\hline OMN & Oman & 1 & 1.04 & 0.46 & 0.42 & 0.07 & 0.08 & 16.64 & 0.94 & 12.33 \\
\hline PAK & Pakistan & 1 & 1.25 & 0.53 & 0.32 & 0.14 & 0.29 & 4.26 & -0.27 & 14.63 \\
\hline PAN & Panama & 0 & 1.39 & 0.59 & 0.27 & 0.12 & 0.34 & 4.20 & -0.06 & 12.59 \\
\hline PNG & Papua New Guinea & 1 & 2.70 & 0.80 & 0.11 & 0.02 & 0.39 & 10.43 & 0.70 & 13.59 \\
\hline PRY & Paraguay & 0 & 1.01 & 0.41 & 0.40 & 0.33 & 0.34 & 1.57 & 0.05 & 13.15 \\
\hline PER & Peru & 0 & 1.16 & 0.50 & 0.37 & 0.12 & 0.19 & 6.97 & -0.48 & 12.26 \\
\hline PHL & Philippines & 1 & 1.10 & 0.47 & 0.37 & 0.19 & 0.26 & 3.73 & -1.19 & 13.59 \\
\hline POL & Poland & 0 & 1.30 & 0.57 & 0.28 & 0.15 & 0.38 & 2.96 & -1.60 & 12.85 \\
\hline PRT & Portugal & 0 & 1.73 & 0.68 & 0.19 & 0.07 & 0.40 & 5.05 & -0.12 & 13.81 \\
\hline PRI & Puerto Rico & 0 & 2.91 & 0.88 & 0.05 & 0.02 & 0.74 & 4.09 & 0.74 & 14.66 \\
\hline REU & Reunion & 0 & 1.87 & 0.80 & 0.09 & 0.06 & 0.70 & 2.04 & 0.63 & 14.29 \\
\hline ROM & Romania & 0 & 1.28 & 0.58 & 0.26 & 0.18 & 0.46 & 2.02 & -1.44 & 12.56 \\
\hline RWA & Rwanda & 1 & 5.81 & 0.92 & 0.04 & 0.00 & 0.46 & 23.69 & 1.87 & 14.18 \\
\hline SAU & Saudi Arabia & 0 & 1.48 & 0.63 & 0.23 & 0.11 & 0.40 & 3.68 & 0.15 & 13.18 \\
\hline SEN & Senegal & 1 & 2.69 & 0.78 & 0.14 & 0.02 & 0.25 & 18.28 & 1.08 & 12.78 \\
\hline SYC & Seychelles & 0 & 1.97 & 0.79 & 0.10 & 0.05 & 0.65 & 2.75 & 1.64 & 14.46 \\
\hline SLE & Sierra Leone & 1 & 1.45 & 0.68 & 0.17 & 0.13 & 0.60 & 1.58 & 1.20 & 15.37 \\
\hline SGP & Singapore & 0 & 3.03 & 0.97 & 0.00 & 0.00 & 0.97 & 1.03 & 0.34 & 16.96 \\
\hline SOM & Somalia & 1 & 1.58 & 0.76 & 0.11 & 0.09 & 0.72 & 1.25 & -0.20 & 12.79 \\
\hline ZAF & South Africa & 0 & 1.76 & 0.73 & 0.14 & 0.07 & 0.57 & 2.84 & -0.89 & 12.35 \\
\hline SUN & Soviet Union & 0 & 1.14 & 0.63 & 0.18 & 0.26 & 0.72 & 0.22 & -2.01 & 14.35 \\
\hline ESP & Spain & 0 & 1.90 & 0.75 & 0.13 & 0.06 & 0.57 & 3.31 & -0.42 & 14.09 \\
\hline LKA & Sri Lanka & 1 & 1.14 & 0.49 & 0.35 & 0.19 & 0.29 & 3.31 & -0.21 & 14.72 \\
\hline SDN & Sudan & 1 & 1.88 & 0.70 & 0.18 & 0.05 & 0.36 & 6.71 & -0.07 & 11.95 \\
\hline SUR & Suriname & 0 & 1.44 & 0.63 & 0.22 & 0.13 & 0.48 & 2.54 & 1.10 & 14.34 \\
\hline SWZ & Swaziland & 0 & 1.02 & 0.44 & 0.42 & 0.18 & 0.20 & 4.93 & 0.86 & 12.92 \\
\hline SWE & Sweden & 0 & 2.12 & 0.86 & 0.06 & 0.04 & 0.79 & 1.88 & -0.34 & 14.53 \\
\hline $\mathrm{CHE}$ & Switzerland & 0 & 2.25 & 0.86 & 0.06 & 0.03 & 0.77 & 2.30 & -0.30 & 14.36 \\
\hline
\end{tabular}




\begin{tabular}{|c|c|c|c|c|c|c|c|c|c|c|}
\hline $\begin{array}{c}\text { WB } \\
\text { Country } \\
\text { Code }\end{array}$ & Country & $\begin{array}{c}\text { Dummy = } 1 \\
\text { if in low } \\
\text { output } \\
\text { equilibria }\end{array}$ & $\begin{array}{c}\text { Ratio } \\
\text { of output } \\
\text { across } \\
\text { two equilibria }\end{array}$ & $\begin{array}{c}\text { Agricultural } \\
\text { labor share } \\
\text { in low } \\
\text { equilibria }\end{array}$ & $\begin{array}{l}\text { Agricultural } \\
\text { labor share } \\
\text { in high } \\
\text { equilibria }\end{array}$ & $\begin{array}{l}\text { Agricultural } \\
\text { capital share } \\
\text { in low } \\
\text { equilibria }\end{array}$ & $\begin{array}{c}\text { Agricultural } \\
\text { capital share } \\
\text { in high } \\
\text { equilibria }\end{array}$ & $\begin{array}{c}\text { Equilibrium } \\
\text { wage wedge }\end{array}$ & $\begin{array}{l}\text { Manufacturing } \\
\text { total } \\
\text { factor } \\
\text { productivity }\end{array}$ & $\begin{array}{c}\text { Agricultural } \\
\text { total } \\
\text { factor } \\
\text { productivity }\end{array}$ \\
\hline$\overline{\text { SYR }}$ & Syrian Arab Republic & 0 & 1.05 & 0.45 & 0.34 & 0.36 & 0.47 & 0.71 & 0.34 & 15.44 \\
\hline OAN & Taiwan & 0 & 1.72 & 0.66 & 0.22 & 0.06 & 0.31 & 7.17 & -0.33 & 14.68 \\
\hline TZA & Tanzania & 1 & 2.94 & 0.85 & 0.07 & 0.02 & 0.56 & 6.91 & -0.13 & 12.15 \\
\hline THA & Thailand & 1 & 1.79 & 0.65 & 0.24 & 0.04 & 0.18 & 14.66 & -0.38 & 13.21 \\
\hline TGO & Togo & 1 & 1.63 & 0.66 & 0.21 & 0.08 & 0.40 & 4.43 & -0.16 & 12.16 \\
\hline TTO & Trinidad and Tobago & 0 & 2.32 & 0.79 & 0.11 & 0.03 & 0.52 & 5.42 & 0.55 & 13.99 \\
\hline TUN & Tunisia & 0 & 1.27 & 0.55 & 0.30 & 0.14 & 0.32 & 3.76 & 0.30 & 13.64 \\
\hline TUR & Turkey & 1 & 1.30 & 0.55 & 0.32 & 0.09 & 0.20 & 7.85 & -0.42 & 13.40 \\
\hline UGA & Uganda & 1 & 2.88 & 0.85 & 0.07 & 0.02 & 0.60 & 6.05 & 0.68 & 13.87 \\
\hline GBR & United Kingdom & 0 & 2.20 & 0.92 & 0.02 & 0.02 & 0.91 & 1.02 & -0.87 & 14.89 \\
\hline USA & United States & 0 & 2.36 & 0.91 & 0.03 & 0.02 & 0.87 & 1.60 & -1.51 & 13.86 \\
\hline URY & Uruguay & 0 & 1.36 & 0.70 & 0.15 & 0.15 & 0.70 & 0.82 & 0.03 & 13.62 \\
\hline VEN & Venezuela & 0 & 1.67 & 0.75 & 0.12 & 0.08 & 0.66 & 1.88 & -0.32 & 14.00 \\
\hline YEM & Yemen, Rep. & 1 & 1.68 & 0.63 & 0.25 & 0.04 & 0.18 & 13.24 & 1.34 & 13.86 \\
\hline YUG & Yugoslavia, FR (Serbia/Monten & 0 & 1.27 & 0.54 & 0.31 & 0.13 & 0.28 & 4.75 & -1.03 & 12.83 \\
\hline ZMB & Zambia & 1 & 2.44 & 0.75 & 0.16 & 0.02 & 0.23 & 17.69 & -0.41 & 9.27 \\
\hline ZWE & Zimbabwe & 1 & 2.02 & 0.69 & 0.21 & 0.03 & 0.19 & 16.38 & -0.06 & 11.36 \\
\hline
\end{tabular}

\section{References}

[1] Acemoglu, Daron and Fabrizio Zilibotti (2001). "Productivity differences," Quarterly Journal of Economics, 116(2), 563-606.

[2] Antweiler, Werner and Daniel Trefler (2000). "Increasing returns and all that: a view from trade," NBER working paper no. 7941.

[3] Azariadis, Costas (1996). "The economics of poverty traps Part One: complete markets," Journal of Economic Growth, 1(4): 449-486.

[4] Azariadis, Costas (2001). "The theory of poverty traps: what have we learned?", Manuscript, UCLA, July.

[5] Backus, David K., Patrick J. Kehoe and Timothy J. Kehoe. (1992). "In search of scale effects in trade and growth," Journal of Economic Theory 58 (3): 377 $-409$.

[6] Banerjee, Abhijit and Andrew F. Newman. (1998). "Information, the dual economy, and development," The Review of Economic Studies 65 (4): 631 653.

[7] Basu, Susanto and David N. Weil. (1998). "Appropriate technology and growth," Quarterly Journal of Economics 113 (4): 1025 - 1054.

[8] Benhabib, Jess and Roger E. A. Farmer. (1996). "Indeterminacy and sectorspecific externalities," Journal of Monetary Economics, 37, 421-443. 
[9] Burnside, Craig. (1996). "Production function regressions, returns to scale, and externalities," Journal of Monetary Economics 37 (2): 177 - 201.

[10] Caballero, Ricardo and Richard K. Lyons. (1992). "The case for external economies," Political Economy, Growth, and Business Cycles (A. Cukierman et al, Eds.). Cambridge, MA: MIT Press.

[11] Caselli, Francesco and Wilbur John Coleman II. (2000). "The world technology frontier," CEPR discussion paper no. 2584.

[12] Christensen, Laurits R., Dianne Cummings, and Dale W. Jorgenson (1981). "Economic growth, 1947 - 1973: an international comparison," European Economic Review 16 (1): 61 - 94.

[13] Collins, Susan and Barry Bosworth. (1996). "Economic growth in East Asia: accumulation versus assimilation," Brookings Papers on Economic Activity 0 (2): $135-191$.

[14] Durlauf, Steven and Danny T. Quah (1999). "The New Empirics of Economic Growth," in John B. Taylor and Michael Woodford (eds.) Handbook of Macroeconomics, North-Holland: Amsterdam, pp. 231-304.

[15] Ethier, Wilfred J. (1982a). "National and international returns to scale in the modern theory of international trade," American Economic Review 72 (3): $389-405$.

[16] Ethier, Wilfred J. (1982b). "Decreasing costs in international trade and Frank Graham's argument for protection,” Econometrica 50 (5): 1243 - 1268.

[17] Food and Agricultural Organization. (1989). FAO Yearbook: Production. Rome: Food and Agricultural Organization.

[18] Foster, Dean and Peyton Young (1990). "Stochastic Evolutionary Game Dynamics," Theoretical Population Biology 38 (2): 219 - 232

[19] Frankel, David and Ady Pauzner (2000). "Resolving indeterminacy in dynamic settings: the role of shocks," Quarterly Journal of Economics, 115(1), 285-304.

[20] Fujita, Masahisa, Paul Krugman and Anthony J. Venables. (1999). The Spatial Economy: Cities, Regions, and International Trade. Cambridge, MA: MIT Press.

[21] Graham, Bryan S. (2000). Poverty Traps and the World Economy. M.Phil Thesis, Oxford University. 
[22] Hall, Robert E. and Charles I. Jones. (1999). "Why do some countries produce so much more output per worker than others?" Quarterly Journal of Economics $114(1)$ : 84 - 116.

[23] Herrendorf, Berthold, Ákos Valentinyi and Robert Waldmann (2000). "Ruling out multiplicity and indeterminacy: the role of heterogeneity," Review of Economic Studies, 67, 295-307.

[24] Hertel, Thomas W. (1997). Global Trade Analysis: Modelling and Applications. Cambridge: Cambridge University Press.

[25] Howitt, Peter and R. Preston McAfee. (1988). "Stability of equilibria with externalities," Quarterly Journal of Economics 103 (2): 261 - 277.

[26] Jones, Charles I. (1997). "On the evolution of the world distribution of income," Journal of Economic Perspectives 11 (3): 19 - 36.

[27] Klenow, Peter J. and Andrés Rodríguez-Clare. (1997). "The neo-classical revival in growth economics: has it gone too far?" in NBER Macroeconomics Annual 1997 (B.S. Bernanke \& J.J. Rotemberg, Eds.), pp. 73 - 114. Cambridge, MA: The MIT Press.

[28] Kremer, Michael, Alexei Onatski and James Stock. (2001). "Searching for prosperity," NBER working paper no. 8250.

[29] Krugman, Paul. (1991). "History versus expectations," Quarterly Journal of Economics 106 (2): 651 - 667.

[30] Krugman, Paul. (1995). Development, Geography, and Economic Theory. Cambridge, MA: MIT Press.

[31] Kuznets, Simon (1966). Modern economic growth. Yale University Press, New Haven.

[32] Landon-Lane, John S. and Robertson, Peter E. (2000). "Post war industrialization and growth: what can a Lewis type model explain?" Manuscript, University of New South Wales, December.

[33] Mankiw, N. Gregory, David Romer and David N. Weil. (1992). "A contribution to the empirics of economic growth," Quarterly Journal of Economics $107(2): 407-437$.

[34] Martin, Will and Devashish Mitra. (2001). "Productivity growth and convergence in agriculture and manufacturing," Economic Development and Cultural Change, 49(2), 403-422. 
[35] Matsuyama, Kiminori. (1991). "Increasing returns, industrialization and indeterminancy of equilibrium," Quarterly Journal of Economics 106 (2): 617 -650 .

[36] Mitchell, Brian R. (1998a). International Historical Statistics - the Americas, 1750 - 1993. London: MacMillan Reference.

[37] Mitchell, Brian R. (1998b). International Historical Statistics - Europe, 1750 - 1993. London: MacMillan Reference.

[38] Mitchell, Brian R. (1998c). International Historical Statistics - Africa, Asia, and Oceania, 1750 - 1993. London: MacMillan Reference.

[39] Mookherjee, Dilip and Anthony F. Shorrocks. (1982). "A decomposition analysis of the trend in UK income inequality," Economic Journal 92 (368): 886 $-902$.

[40] Murphy, Kevin M., Andrei Shleifer and Robert W. Vishny. (1989). "Industrialization and the big push," Journal of Political Economy 97 (5): 1003 1020 .

[41] Myrdal, Gunnar. (1957). Economic Theory and Under-developed Regions. London: Duckworth.

[42] Nurkse, Ragnar (1953). Problems of Capital Formation in Underdeveloped Countries. New York: Oxford University Press.

[43] Pangariya, Arvind. (1981). "Variable returns to scale in production and patterns of specialization," American Economic Review 71 (2): 221 - 230.

[44] Prescott, Edward C. (1998). "Needed: A theory of total factor productivity," International Economic Review 39 (3): 525 - 551.

[45] Quah, Danny. (1993). "Empirical cross-section dynamics in economic growth," European Economic Review 37 (2-3): 426 - 434.

[46] Quah, Danny (1997). "Empirics for Growth and Distribution: Stratification, Polarization, and Convergence Clubs," Journal of Economic Growth 2 (1): $27-59$.

[47] Rodrik, Dani. (1995). "Getting interventions right: how South Korea and Taiwan grew rich," Economic Policy 0 (20): 53 - 97. 
[48] Rodrik, Dani. (1996). "Coordination failure and government policy: a model with applications to East Asia and Eastern Europe," Journal of International Economics 40 (1-2): 1 - 22.

[49] Romer, Paul. (1986). "Increasing returns and long-run growth," Journal of Political Economy 94 (5): 1002 - 1037.

[50] Rosenstein-Rodan, P.N. (1943). "Problems with industrialization of Eastern and South-eastern Europe," Economic Journal 53 (210/211): 202 - 211.

[51] Sheather, S.J. and M.C. Jones. (1991). "A reliable data-based bandwidth selection method for kernel density estimation," Journal of the Royal Statistical Society B, 53 (3), 683 - 690.

[52] Shorrocks, Anthony F. (1980). "The class of additively decomposable inequality measures," Econometrica 48 (3): 613 - 625.

[53] United Nations, Statistical Office. (1980). Yearbook of National Accounts Statistics. New York: United Nations.

[54] United Nations. (1991). National Accounts Statistics: Main Aggregates and Detailed Tables. New York: United Nations.

[55] United Nations. (1994). National Accounts Statistics: Main Aggregates and Detailed Tables. New York: United Nations.

[56] United Nations. (1995). National Accounts Statistics: Main Aggregates and Detailed Tables. New York: United Nations.

[57] United Nations, Statistical Division. (1999). Statistical Yearbook CD-ROM. New York: United Nations.

[58] World Bank. (2000). World Development Indicators 2000 CD-ROM. Washington D.C.: The World Bank. 